\title{
Fuel cell catalyst degradation: Identical location electron microscopy and related methods
}

Matthias Arenz $^{* a, b}$ and Alessandro Zana ${ }^{a}$

${ }^{a}$ Nano-Science Center, Department of Chemistry, University of Copenhagen, Universitetsparken 5, DK-2100 Copenhagen $\varnothing$, Denmark

${ }^{b}$ Department of Chemistry and Biochemistry, University of Bern, Freiestrasse 3, 3012 Bern, Switzerland

* Corresponding Author: matthias.arenz@dcb.unibe.ch

\begin{abstract}
Fuel cells are an important piece in our quest for a sustainable energy supply. Although there are several different types of fuel cells, the by far most popular is the proton exchange membrane fuel cell (PEMFC). Among its many favorable properties are a short start up time and a high power density; both essential for automotive applications. Its drawback is the use of carbon supported Pt or Pt alloys as the active catalyst. The scarce resources of Pt led to significant efforts in reducing the amount of Pt used in PEMFCs. Thanks to the advancements of these efforts, catalyst stability gained increasing focus. Activity of the catalyst is important, but stability is essential. In the presented perspective paper, we review recent efforts to investigate fuel cell catalysts ex-situ in electrochemical half-cell measurements. Due to the amount of different studies, this review has no intention to give a complete overview and cover all studies. Instead we concentrate on efforts of our and other research groups to apply identical location electron microscopy and related methods to study the degradation of PEMFC catalysts.
\end{abstract}

Keywords: Pt; proton exchange membrane fuel cells; degradation; IL-TEM; IL-SEM; ex-situ investigations 


\section{Introduction}

A sustainable (renewable), cost efficient supply of energy is one, if not the most important challenge for our future. Not only is the supply of affordable energy the driving force for many developments, sustainable energy supply will also help us facing the many environmental challenges that are related to the use of non-renewable energy. As most renewable energy sources, e.g. solar and wind energy, deliver transient, electric energy, the alignment of supply and demand is tightly related to sustainable energy. That is, in addition to develop the use solar and wind energy, we also need to provide solutions to convert, store and re-convert large amounts of electric energy. This is where electrolyzers and fuel cells come into play. They potentially offer the means of aligning our energy production to the demand with the help of energy carriers such as hydrogen.

It is beyond the scope of the this perspective review to discuss this framework; however, to provide viable solutions to above outlined challenge, fuel cells - the devices that convert the energy carrier back to electricity - need to be efficient and cost effective. For both properties the catalyst for the oxygen reduction reaction is essential. It needs to be highly active and to consist of reasonable abundant materials. Although Pt based catalysts most likely cannot provide long term solutions, today they offer the most promising pathway for commercialization of a range of fuel cells. This is largely due to the impressing advances that have been made in optimizing the activity of Pt, e.g. by alloying with a second metal [1-3]. With these advances the long term stability of industrial type high surface area carbon supported catalysts, here denoted as $\mathrm{Pt} / \mathrm{C}$ or $\mathrm{PtM} / \mathrm{C}$, gained increasing attention. Activity and power targets are not the main concerns anymore, instead stability has become a paramount challenge [4].

There has been extensive literature published regarding the performance degradation of fuel cells and their catalysts [5-8]. Most of these studies have been conducted in-situ, i.e. in membrane electrode assemblies (MEAs) or fuel cell stacks, as their performance is the ultimate test for the use of consumers. In this perspective review, we limit ourselves to ex-situ methodologies, i.e. studies using electrochemical half-cells. Ex-situ studies cannot completely substitute in-situ investigations, but half-cell measurements provide a faster and cheaper way to scrutinize the stability of $\mathrm{Pt} / \mathrm{C}$ based catalysts. Moreover a complete analysis of the degradation mechanism of fuel cell catalysts using in-situ techniques is not straightforward, whereas ex-situ studies allow a better control of the individual experimental parameters [9]. Nevertheless, ex-situ stability investigations are far less common used than ex-situ activity investigations [10] of catalysts and sometimes their scientific and predictive value is even questioned. This might be related to the fact that the majority of ex-situ 
stability investigations of fuel cell catalysts simply report the loss in active surface area of the catalyst upon potential cycling. In view of this, in the recent years significant effort was put in the development of more sophisticated ex-situ stability investigation methodologies combining different characterization techniques. For example, half-cell measurements can easily be combined with differential electrochemical mass spectroscopy (DEMS) providing information about gaseous reaction products linked to the oxidation of the carbon support [11-15]. In this work, we concentrate on the combination of conventional half-cell measurements determining surface area loss with microscopic techniques developed to track morphological changes of the catalysts material at the nanoscale level, so called identical location electron microscopy.

\section{Approaches for half-cell degradation studies}

\subsection{Experimental setup and protocols}

In this section we will focus on the experimental protocols used to evaluate the durability of high surface area catalysts using $e x$-situ methodologies, i.e. measurements performed in electrochemical half-cells. Keeping in mind that ex-situ studies cannot completely replace in-situ investigations (i.e. studying MEAs and stacks), such studies provide i) a faster and cheaper way to screen the performance of catalysts and ii) a suitable tool for mechanistic studies of catalyst aging. By comparison a complete analysis of the degradation behavior using in-situ techniques is highly complex and the degradation is not necessarily an intrinsic property of the catalyst itself, but more of the catalyst layer. That is, in a fuel cell several parameters can influence the catalysts durability, such as relative humidity, partial pressures of the gases, temperature; but more importantly, also extrinsic factors as the quality of the MEA preparation itself. The same catalyst can perform quite differently in measurements applying the same degradation protocol depending on the MEA fabrication - which is in general proprietary knowledge. Furthermore in-situ degradation measurements last several days and up to several months [16].

In a conventional half-cell set up a three electrode configuration is adopted. A reference (RE), working (WE) and counter electrode (CE) are placed within the cell; they might be placed in three different compartments or in the same compartment. This configuration permits to probe the current potential relation at the WE with respect of the RE disregarding the interfacial potential difference of the CE. As in catalyst activity investigations, in ex-situ degradation studies the choice of right components is extremely important. The choice of RE and WE is relatively straightforward. Some of the most common RE electrodes are the Standard Calomel Electrode (SCE) and the $\mathrm{Ag} / \mathrm{AgCl}$ 
electrode. These electrodes have the advantage of a high stability (measurements can take more than 12 hours), but they might introduce contaminations into the system. In commercial ex-situ setups often all electrodes are simply placed into the same glass cell. However, even in double walled REs some ion exchange with the surrounding electrolyte might occur, thus poisoning the catalyst material. To avoid the diffusion of unwanted ions such as chlorides into the electrolyte, it is advisable to place the RE electrode in a separated compartment. In order minimize the iR drop between WE and RE while providing electrical contact and electrolyte exchange with the main compartment, in general a porous glass frit is placed at the bottom of the glass cell acting as Luggin capillary. An alternative separation method that completely avoids electrolyte exchange between the compartments can be achieved by using a Nafion membrane as barrier [17]. The WE in general consists of a Teflon tip with an embedded glassy carbon disk onto which the catalyst suspension is pipetted to form a catalyst film for the activity and/or macroscopic stability test [18-22].

The choice of the CE electrode and proper iR compensation are perhaps the most important aspect to consider. Most commonly a Pt mesh is used as CE in half-cell measurements. However, one needs to consider that the CE potential is free floating and the applied CE potential under fast cycling can change between very high and low values. Under these conditions severe Pt dissolution can take place and in the worst case Pt ions can redeposit onto the catalyst at the WE [23, 24]. Therefore non Pt materials are preferred as CE in degradation tests. A good alternative is to use a glassy carbon rod with high surface area or if still Pt is the CE material of choice it should be placed in separated compartment in the same fashion as discussed before for the RE to confine the Pt ions [25].

Furthermore, one needs to careful check that the chosen potential window is indeed applied at the WE. Depending on potentiostat and software used, this may seem as being the case, but indeed is not. As often several thousand potential scans or potential steps are applied in a degradation tests, see below, and during fast potential cycling dissolution increases exponentially with the potential [26], small variations in the upper or lower potential limit can significantly influence the results. Deviations between the (by the software) selected and the applied potential window can occur for two reasons, the $\mathrm{CE}$ and improper $\mathrm{iR}$ compensation. If the $\mathrm{CE}$ area is too small, the applied potential might be limited by the potentiostat specification as large potentials/currents have to go through the CE. Often this is not seen in the recording software and can only be discovered by measuring the potential between RE and WE independent of the potentiostat software. Furthermore, if the iR drop is not properly compensated the measured and actual potential limits deviate. A good 
test is therefore to take a Pt WE and record a CV series between 0.05 and $1.2 \mathrm{~V}_{\mathrm{RHE}}$ increasing the scan speed from 0.1 to $10 \mathrm{~V} \mathrm{~s}^{-1}$. With proper $\mathrm{iR}$ compensation, normalizing the currents to the scan speed in the $\mathrm{H}_{\text {upd }}$ region of $\mathrm{Pt}$ the currents should exactly overlap, while the sluggish $\mathrm{Pt}$ oxidation leads to changes at higher potentials, see figure 1 [27].

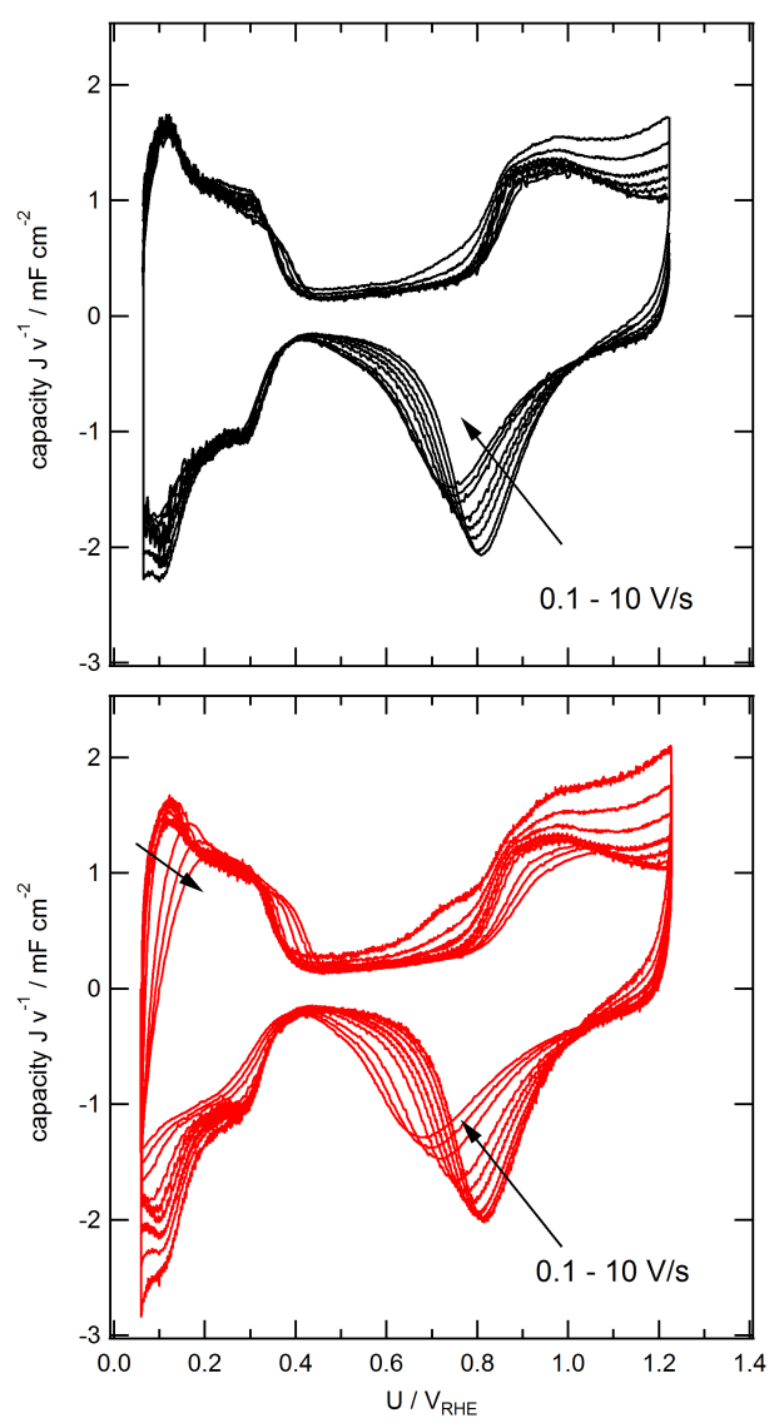

Figure 1: Comparison of a CV of polycrystalline Pt normalized to the scan speed; with (upper figure) and without (lower figure) proper $\mathrm{iR}$ compensation applied during the measurement. The scan speed varied between 0.1 and $10 \mathrm{~V} \mathrm{~s}^{-1}$, the electrolyte was Ar saturated 0.1 M HClO4 solution.

Beside the experimental setup, the choice of potential treatment is essential. The accelerated stress test (AST) treatment must be designed to serve two purposes. First it has to provide a fundamental understanding of the physical and chemical degradation processes. Only a fundamental understanding of the different degradation mechanisms like Ostwald ripening, particle migration and coalescence, particle detachment and carbon corrosion will enable the design of considerably 
more durable catalysts than current standards. The second aim of an AST treatment should be to provide information about the degradation of the catalyst under realistic working conditions. A large variety of AST protocols have been presented in literature, consisting of potential holds, potential cycling with different scan rates, different temperatures, with or without rotation and different gas atmospheres. This variety of different AST treatments considerably limits comparability between different studies. Furthermore, only few AST treatments are designed by groups of experts with knowledge in both in-situ and ex-situ degradation studies. The aim of the AST treatment must be to simulate potentials and currents experienced by the catalyst in PEMFCs. At the same time the duration of the AST should be limited to avoid contamination effects. It is therefore important when choosing one AST over another, to carefully consider what the main purpose of the AST treatment should be $[28,29]$. That is for which application the PEMFC catalyst should be tested. Applying an AST protocol that simulates high potential cycling on a catalytic material that will be employed to work under constant potential conditions will not provide useful information on the degradation behavior of the catalyst being tested.

The fundamental aim of an AST treatment is to accelerate the degradation of the catalyst enabling one to predict the life time performance of the device in use. Under normal operation conditions the performance decay of a PEMFC covers months and/or years. The challenge for meaningful AST treatment protocols is to simulate in few hours/days what the PEMFC will experience in its whole lifetime.

Among the plethora of AST protocols proposed and used in literature, it is worth highlighting the AST proposed by the fuel cell commercialization conference of Japan (FCCJ) together with three automotive manufactures [29]. The degradation protocol proposed was designed with the aim of simulating condition experience by Fuel Cell Vehicles (FCVs) during start/stop and load cycles. The FCCJ provides a protocol to test the catalyst material not only in-situ in MEAs, but also for $e x$ situ measurements in half-cell set ups. An alternative AST protocol for ex-situ measurements is provided by the Department of Energy (DOE) [30]. The main difference between the FCCJ and DOE protocols is the applied scan speed and hold time, respectively. The DOE protocol applies slower scan rates and longer hold times and therefore lasts considerably longer. Without changing the electrolyte it is difficult to maintain clean conditions in ex-situ measurements over a prolonged time; changing the electrolyte on the other hand comprises the risk of mechanical catalyst loss. The authors adhere to the FCCJ AST protocol, but typically limit the measurement time to less than 24 h. 
As pointed out by the FCCJ [29], during start/stop the main degradation mode is ascribed to corrosion of the carbon support. In FCVs during shut down at the anode hydrogen gas is gradually replaced by air and thus during start-up the cathode can experience significantly high potentials [6, 31]. In view of this the FCCJ proposed an AST protocol to simulate start/stop that consists of triangular potential waves ranging between 1-1.5 $\mathrm{V}_{\mathrm{RHE}}$ applied at the WE with a scan rate of 500 $\mathrm{mV} \mathrm{s}^{-1}$.

Load cycles are representative of potentials experienced in a FCV during driving operation. For this condition an AST protocol applying a WE potential ranging between 0.6 and $1 \mathrm{~V}_{\mathrm{RHE}}$ is proposed. The former potential corresponds to the potential at the maximum load the stack can experience, while $1 \mathrm{~V}_{\mathrm{RHE}}$ corresponds to idle, i.e. open circuit operation. Under the latter conditions $\mathrm{Pt}$ is in an oxidized form (at $1 \mathrm{~V}_{\mathrm{RHE}}$ ), thus Pt dissolution might be suppressed because Pt dissolution is reported to occur on a bare $\mathrm{Pt}$ surface $[32,33]$. When the potential is then decreased to $0.6 \mathrm{~V}$ RHE $\mathrm{Pt}$ oxide is reduced to bare Pt and dissolves. This continuous change on the state of the Pt surface considerably enhances Pt dissolution [34]; see also the chapter on Pt dissolution of Cherevko et al. in the same special issue [35].

In order to track the performance loss during the AST treatment the electrochemical active surface area (ECSA) is measured at fixed intervals. The ECSA is a crucial parameter for the evaluation of the catalyst degradation because it reflects directly the loss in active sites for the reaction. In halfcell measurements two procedures are commonly adopted to measure the ECSA. The first one consists in calculating the charge that it takes to adsorb/desorb a layer of hydrogen in the $\mathrm{H}_{\text {upd }}$ region. The second consists of oxidizing a pre-adsorbed monolayer of CO. Integrating the charge needed for the oxidation of CO the ECSA can be calculated [36]. Another method worth mentioning is metal, e.g. $\mathrm{Cu}$ or $\mathrm{Pb}$, under-potential deposition [37]. This methodology might be used for the ECSA evaluation in cases where $\mathrm{CO}$ adsorption or $\mathrm{H}_{\text {upd }}$ determination is not feasible. However the method is not optimal because the metal ions stay in solution and can alter the catalytic performance and/or the degradation behavior.

$\mathrm{H}_{\text {upd }}$ and CO stripping techniques are both suitable methods for ECSA determination. However as shown by Mayrhofer et al. a proper background subtraction is needed in order to minimize errors [20]. This might not be trivial when the carbon support of the catalyst during AST becomes highly oxidized. The oxidation of the carbon support leads in some cases to a massive increase in pseudocapacity, therefore subjecting the determination of the $\mathrm{H}_{\text {upd }}$ area to large errors. Furthermore, the interaction of the catalyst with hydrogen might be changed, e.g. due to alloying of Pt [38]. Thus 
the amount of $\mathrm{H}_{\text {upd }}$ charge per unit changes in an unknown way leading to an additional error source.

The ECSA area determination by CO stripping needs a proper background subtraction as well. However because the potential region of interests in case of $\mathrm{CO}$ oxidation is less affected by the enlargement of the carbon pseudocapacity and $\mathrm{CO}$ binds stronger than hydrogen to Pt, the ECSA determination is less affected by experimental errors. As a general rule, because $\mathrm{H}_{\text {upd }}$ is easily accessible a comparison of the ECSA values determined by the $\mathrm{H}_{\text {upd }}$ and $\mathrm{CO}$ stripping procedure is always beneficial. However, care should be taken when measuring the ECSA within the same AST protocol. Recently was demonstrated that CV measurements performed in order to determine the $\mathrm{H}_{\text {upd }}$ area enhance the ECSA loss [39, 40]. Furthermore it was shown that some reactive gasses like CO enhance the ECSA loss if not carefully removed from the bulk of the electrolyte [41].

Finally, it is worth mentioning that despite the large amount of AST protocols, catalysts and experimental conditions applied, what still is missing is a cross laboratory experimental half-cell study using a standard benchmark catalyst. A standardization of the experimental conditions for half-cell studies would be extremely beneficial because half-cell studies are far less complicated then MEA investigations and offer a better control over the experimental parameters.

\subsection{Degradation studies on Particle Model Systems}

In the previous section we discussed the advantages of using half-cell measurements over in-situ characterization techniques to study catalyst degradation. One of the advantages, we emphasized the possibility to combine different characterization techniques with half-cell measurements monitoring the surface area loss of the active component. In the following we describe two such techniques invented in our laboratory $[42,43]$ that are suitable for mechanistic studies; studies utilizing Cluster deposited on planar carbon films of TEM grids, and Identical-Location Transmission Electron Microscopy (IL-TEM). The first method concentrates on model catalysts, while with IL-TEM industrial fuel cell catalysts are studied. In both methods the basic idea is to study catalysts on TEM grids before and after degradation tests, where the TEM grid has been applied as working electrode. In the method discussed first, the use of planar supports enables a statistical analysis, especially if STEM images instead of TEM images are recorded. In IL-TEM the behavior of individual catalyst areas is tracked, thereby gaining local information on the degradation.

To study particle model systems, the catalyst particles are deposited onto the carbon film of TEM grids. As the TEM grid is used as working electrode in half-cell degradation tests, it is important 
that the grid material is nobler than the catalyst particles. In the case of Pt particles therefore only gold grids can be applied. We preferably apply holey carbon Au TEM grid coated by an additional thin carbon film of $2 \mathrm{~nm}$, which optimizes the image quality. As deposition technique, we used a laser ablation cluster source with the possibility of size selecting the catalyst particles [44-46], but in principle also other deposition techniques are suitable. Important factors for degradation studies however are that the catalyst particles should be free of capping agents or ligands and they should to be randomly distributed on the carbon film of the TEM grid, see figure 2 .
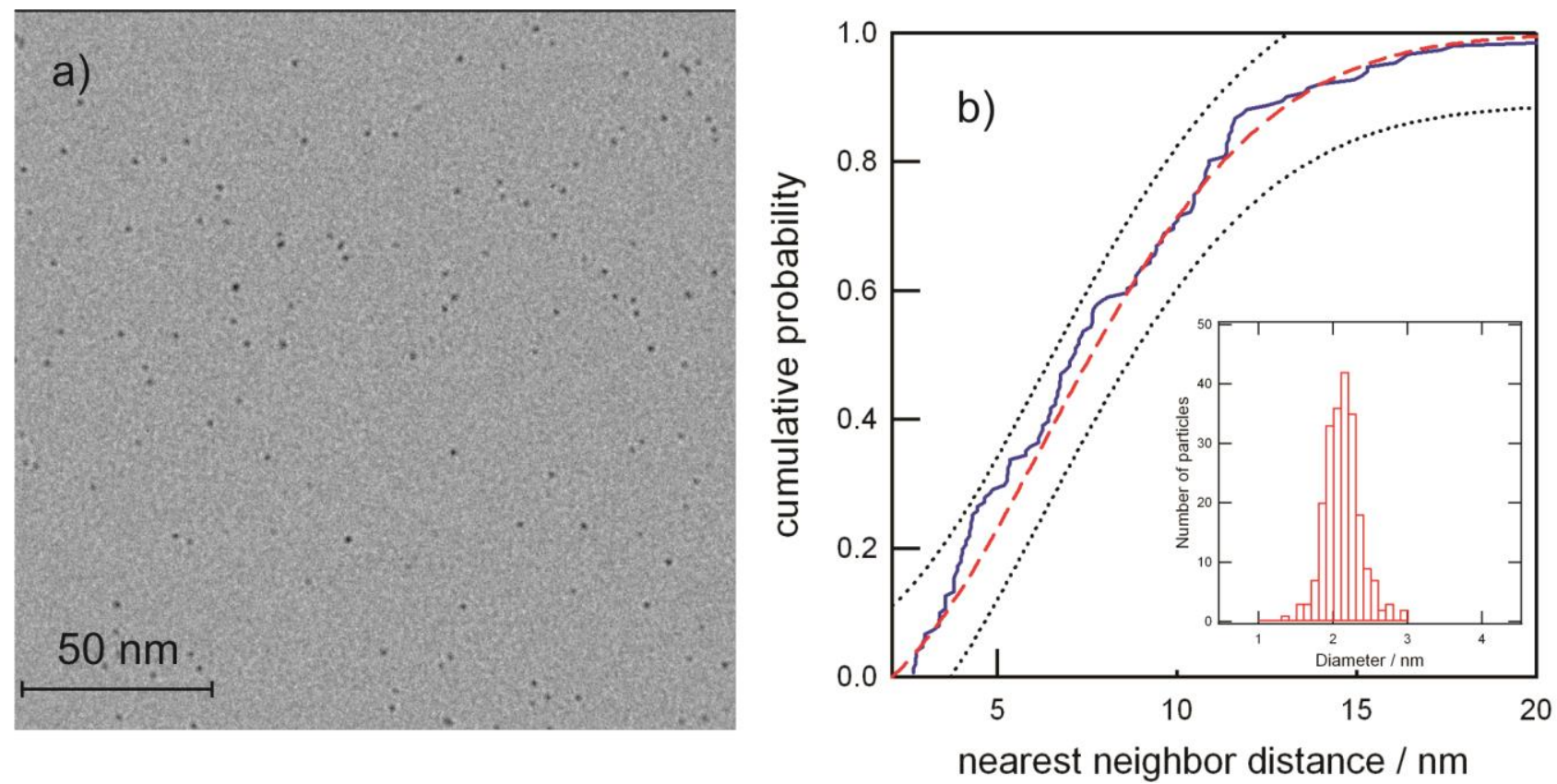

Figure 2: (a) Representative TEM micrograph of a pristine Pt nanocluster sample deposited onto a carbon film of a TEM grid. The Pt nanoclusters were prepared by a laser ablation source and size selected by an electrostatic bender and a pin hole. The cluster coverage can be accurately established via the deposition current. In part (b) it is demonstrated by determining the cumulative nearest neighbor distribution (blue line) in comparison to its theoretical curve assuming (red dashed line) that the Pt nanoclusters are randomly distributed on the carbon film. The dotted black line indicates a five percent statistical significance calculated according to the Kolmogorov-Smirnov test. In the inset the histogram of the particle size is shown. The figure is taken with permission from ref. [45].

After deposition of the catalyst particles a conventional TEM or STEM analysis of the pristine catalyst is performed. As no local information of individual particles is gained, several areas of the sample including many particles should be analyzed. The two dimensional nature of the sample enables the use of software routines for data analysis. Once the initial state of the catalyst particles is established electrochemical degradation studies can be performed. For this the Au TEM grid has 
to be electrically contacted to enable its use as WE. This can be achieved with the help of a metal wire $(\mathrm{Au}$ or $\mathrm{Pt})[42,43]$ or a specific holder can be devised. Using a Pt wire as contact, should be avoided if extensive AST treatments are applied, because Pt dissolution from the wire and redeposition onto the catalyst might occur. Therefore more advanced holders for IL-TEM have been implemented [47, 48]. Recently we developed a grid holder that allows the use of a standard RDE tip, see figure 3; the RDE tip can be GC, Au or Pt depending on the purpose of the experiment. To establish electrical contact, the TEM grid is pressed down onto the RDE tip by a custom made Teflon cap. Care has to be taken that the contact between TEM grid and RDE tip does not lead to a brakeage of the carbon film.

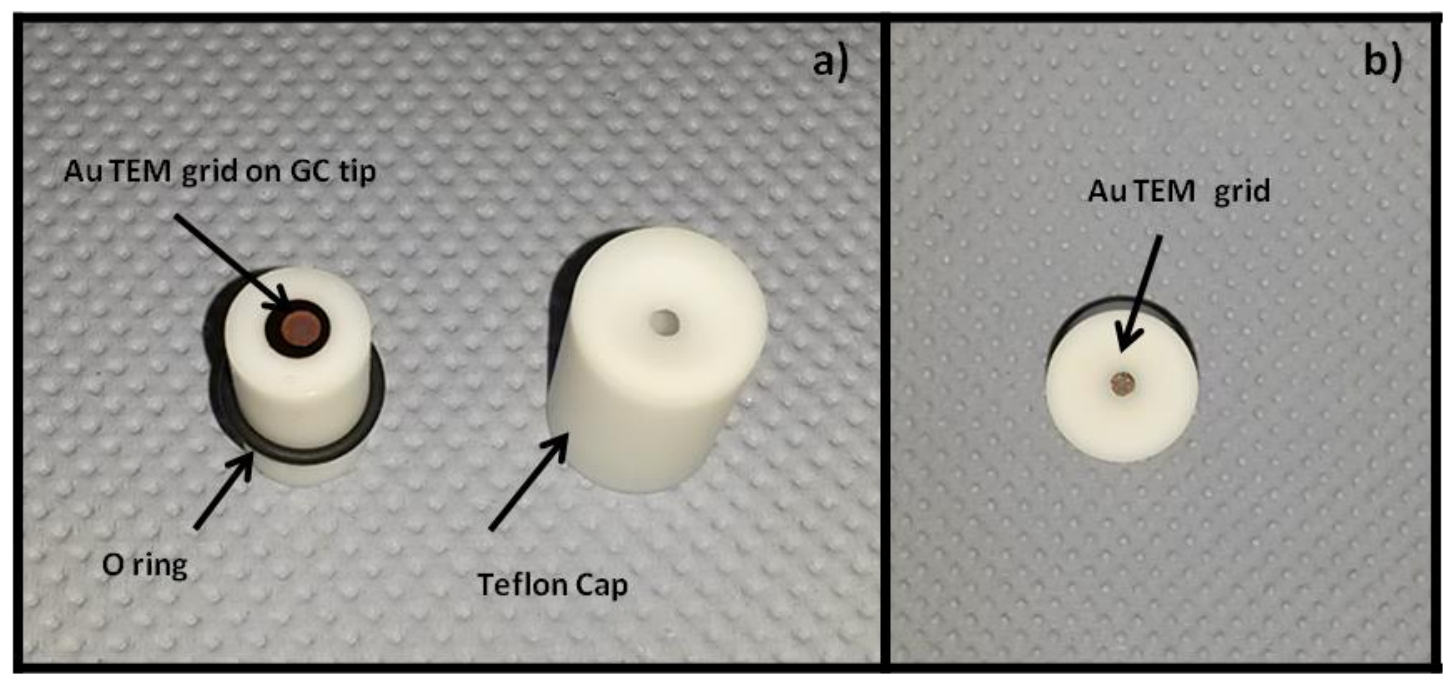

Figure 3. Picture of Au TEM grid placed on a GC substrate of a RDE tip and Teflon cap (a), picture of the TEM gold grid when mounted to the RDE tip with the help of the Teflon cup (b).

Once the TEM grid is attached to the RDE tip, conventional degradation tests in electrochemical half-cells can be applied. As mentioned above, we preferably perform degradation treatments not lasting more than $24 \mathrm{~h}$ in order to limit the influence of contaminations in the electrochemical halfcell. After the electrochemical treatment the TEM grid is dried and transferred back to TEM for imaging. As for IL-TEM, several cycles of electrochemical treatments can be analyzed.

\subsection{IL-TEM as tool for monitoring degradation high surface area catalysts}

In the recent years IL-TEM technique gained considerable attention due to its ease and the ability to trace morphological changes on the same NPs in industrial type, high surface area catalysts. The advantage over a conventional TEM analysis of degraded high surface area (HSA) catalysts is the 
ability to trace the same particles and/or the same area of the catalysts before and after electrochemical aging. In a conventional experimental procedure combining RDE and TEM the fuel cell catalyst is first subjected to an electrochemical half-cell measurement using a RDE and afterwards the catalyst film is scraped off the RDE tip and deposited onto a TEM grid. The catalyst is then compared with the pristine catalyst powder. The limitation of this approach resides in the inhomogeneity of conventional high surface area catalysts and the fact that in a local probe like TEM always a pre-selection of the investigated part of the sample occurs. Such a limitation plays an important role when comparing different high surface area $\mathrm{Pt} / \mathrm{C}$ samples. Even commercial $\mathrm{Pt} / \mathrm{C}$ catalysts have been found to exhibit significant inhomogeneity, which may be a consequence of the inhomogeneity of commercial carbon supports and the often applied calcination step. In some parts of the catalyst the active face therefore might already be agglomerated before the electrochemical treatment. As to our knowledge no automatic particle analysis software to analyze several thousand particles is available, these local differences can lead to inaccurate interpretation.

To overcome at least some of these limitations, IL-TEM can be applied to study fuel cell catalyst degradation. The two main differences between the conventional approach and IL-TEM are the capability of tracing back the same catalyst area before and after the electrochemical measurements and that a TEM finder grid is used as WE, thus the catalyst can be repeatedly investigated after several degradation treatments. 

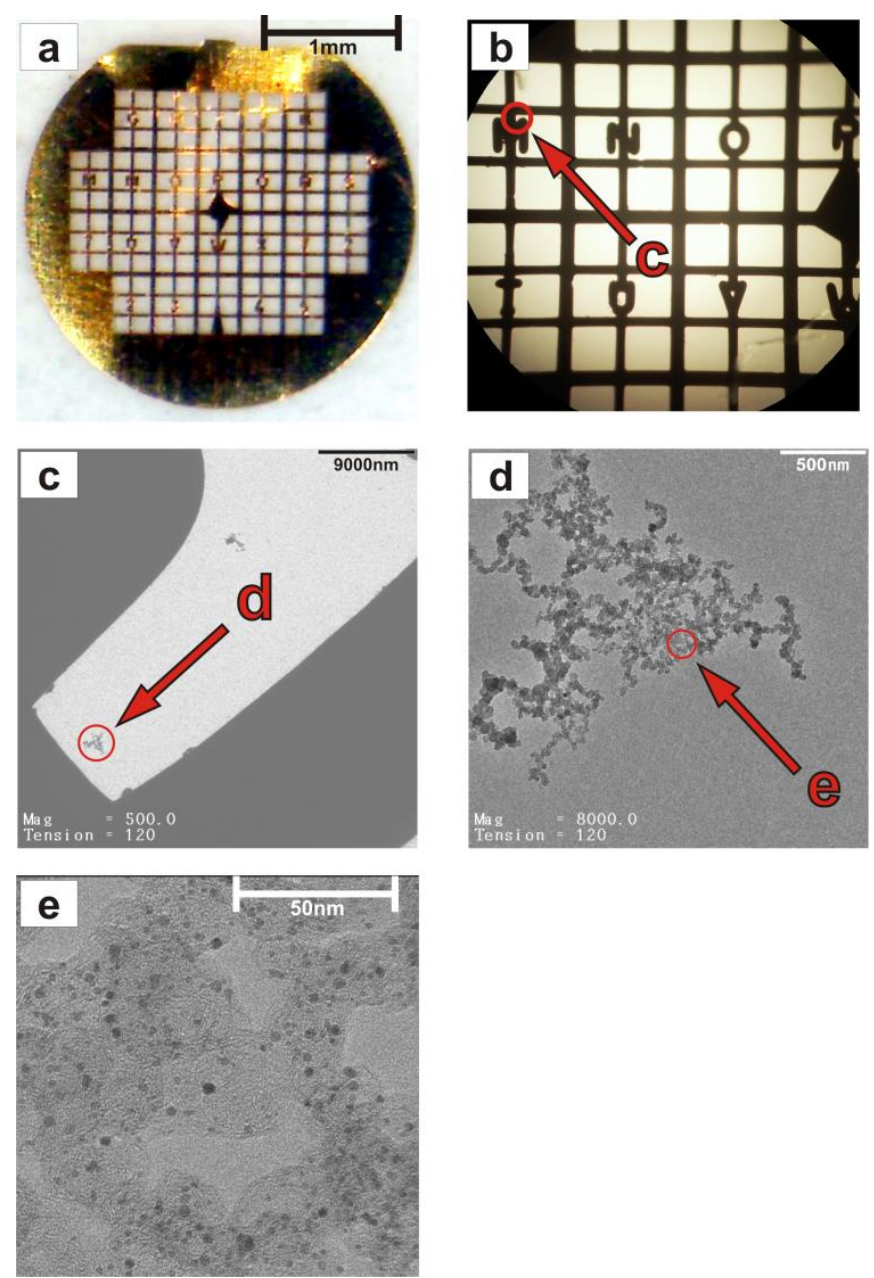

Figure 4. Sketch of the IL-TEM procedure for finding identical locations of the catalyst before and after degradation tests. The standard TEM gold finder grid (a) coated with a thin carbon film is used. By means of the letters and numbers and several intermediate magnifications (steps b-e), different parts of the dried catalyst are defined and their location listed for later re-location. For degradation measurements the TEM grid is inserted into the holder, see figure 3. The figure is adopted from figure 3 in ref. [49].

The basic experimental procedure is as such. A droplet of catalysts ink with proper dilution is cast onto a gold TEM finder grid covered with a thin carbon film and dried. In the next step the initial state of the catalysts is evaluated at different areas. For later analysis several different areas are selected, where the catalyst film forms a thin quasi-2D layer. It is noted, where these areas are and how they can be relocated after the degradation treatment, see figure 4. In order to track back the same catalyst area before and after the electrochemical measurements, the letters and numbers on the TEM grid are used. At low magnification the same spot can be traced back by means of the markers and then by a characteristic shape of the carbon support. After the initial evaluation, the finder grid is transferred into the electrochemical half-cell. For the electrical contact the same 
procedure is applied as previously discussed. As described before, after the electrochemical treatment the TEM finder grid is dried and transferred back to TEM for imaging. IL-TEM can be performed at different stages of the electrochemical treatment by stopping the treatment; several cycles of performing TEM and transferring the grid back into the half-cell are possible [43]. However, care should be taken when performing TEM imaging. As discussed for the potential influence of measuring the ECSA several times during an AST, also IL-TEM can influence the catalyst. In fact the electron beam can alter the sample especially if high dose of electrons is applied; thus it is always preferred to minimize the electron dose on the sample. As a general rule in order to check if the electron beam changes the sample, following the electrochemical measurements TEM analysis should be also performed at pristine locations, i.e. locations which have not been previously exposed to the electron beam [50,51]. If these precautions are taken into account IL-TEM enables a nondestructive investigation of identical catalysts areas before and after electrochemical measurements to follow morphological changes of the catalysts (i.e. carbon corrosion, Ostwald ripening). To some degree it also allows to perform statistics. It goes without saying that IL-TEM is not limited to fuel cell catalysts, but that it also offers great potential to study the degradation of other electroactive systems.

\section{Research Examples}

In the following we demonstrate the half-cell approach for fuel cell catalyst degradation investigations with the help of some selected studies. As in the previous methodical section, we start with two dimensional model systems and then present studies on industrial type, carbon supported high surface area catalysts.

\subsection{Particle migration under electrochemical treatment}

Particle migration and coalescence is one of the degradation channels limiting the live time of fuel cell catalysts. In order to investigate the fundamentals of particle migration on a carbon support, two dimensional model systems are the system of choice. In industrial type, high surface area catalysts the migration of catalyst particles is only difficult to detect. On two dimensional samples, however, it could be unambiguously shown that particle migration does take place under electrochemical treatment even at room temperature. Surprisingly the reactive environment seems to influence if migration leads to coalescence or not. This is demonstrated in figure 5. In fig. 5a) the pristine two dimensional sample of Pt nanoclusters deposited onto the carbon film of a gold TEM is shown. The pristine Pt nanoclusters are randomly distributed and have an average size of about 2 
$\mathrm{nm}$ exhibiting some degree of coalescence due to direct collisions of nanoclusters during deposition in the laser ablation source. After potential cycling in an extended potential window of 0.06-1.06 $\mathrm{V}_{\mathrm{RHE}}$ significant coalescence due to particle migration was observed, see fig. $5 \mathrm{~b}$. The driving force for the particle migration at room temperature is not sufficiently studied; however, we proposed that the process is induced by a continuous change of the Pt surface from hydrophilic to oxophilic and back during the potential cycling. As the particles are deposited on a hydrophobic carbon film, these changes in the surface properties should lead to a continuous change of the particle-support interaction as well, thus triggering random migration. Further more systematic studies are necessary to confirm this model for particle migration upon electrochemical treatment. It has been unambiguously shown, however, that performing the same potential treatment, but in different environment - CO saturated instead of Oxygen or Argon saturated electrolyte - leads to different behavior. In case of CO saturated electrolyte, particle migration occurs as well, but no significant coalescence is observed, see fig. 5c). It seems that the $\mathrm{CO}$ adsorbed on the Pt surface at most of the applied potentials protects the particles from coalescence; similar to an electrostatic repulsion in colloidal particle suspensions. From our point of view work concerning degradation studies on such model systems should be intensified. An essential prerequisite will be a more suitable (less complicated and less time consuming) sample preparation. 


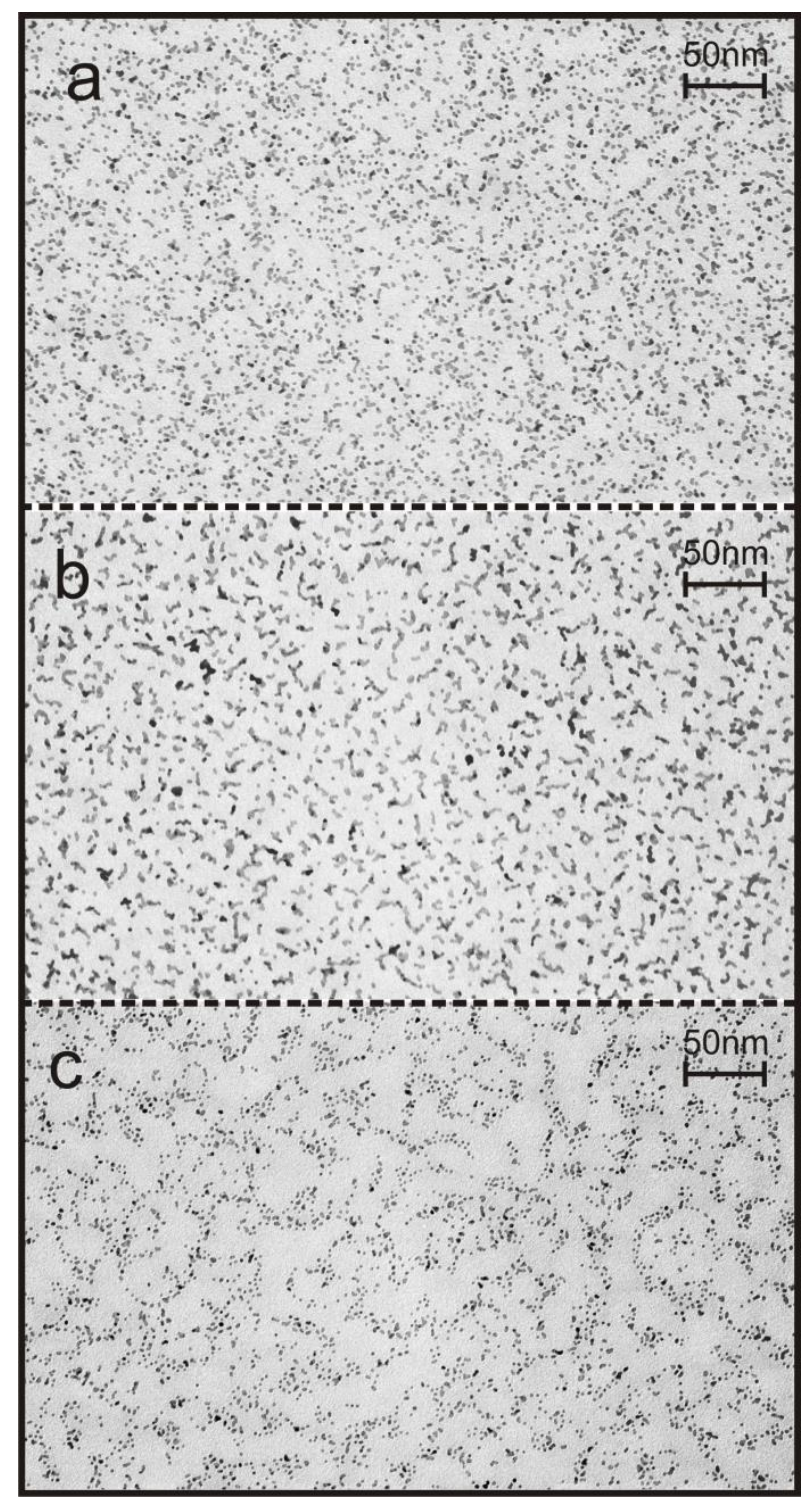

Figure 5. TEM micrographs Pt nanoclusters deposited onto a two dimensional carbon film of a TEM gold grid. (a) Pristine Pt nanoclusters after deposition in a laser ablation source; (b) Pt nanoclusters after electrochemical treatment consisting of 60 potential cycles between 0.06 and 1.06 $\mathrm{V}$ vs. RHE in oxygen saturated $0.1 \mathrm{M} \mathrm{HClO}_{4}$ solution at a sweep rate of $0.05 \mathrm{~V} \mathrm{~s}^{-1}$; c) $\mathrm{Pt}$ nanoclusters after identical electrochemical treatment but in $\mathrm{CO}$ saturated $0.1 \mathrm{M} \mathrm{HClO}_{4}$ solution. The figure is adopted from ref. [49].

\subsection{IL-TEM studies of industrial type high surface area catalysts}

In the following we will discuss some representative IL-TEM studies demonstrating its use for studying the degradation mechanism of industrial type fuel cell catalysts. The catalysts are based on high surface area carbon supported $\mathrm{Pt}$ and $\mathrm{Pt}$ alloy nanoparticles, noted as $\mathrm{Pt} / \mathrm{C}$ and $\mathrm{PtM} / \mathrm{C}$ respectively. As outlined above, the invention of the IL-TEM approach has introduced several 
advantages to the study of catalyst degradation. Before the implementation of IL-TEM several degradation channels for the loss of performance have been reported in literature, but only after the introduction of identical location techniques it has become possible to distinguish among them. Mayrhofer et al. published the first study using IL-TEM on Pt/C catalysts in 2008 [43]. In this study a commercial Pt/C catalyst was subjected to potential cycling from $0.4 \mathrm{~V}_{\mathrm{RHE}}$ to $1.4 \mathrm{~V}_{\mathrm{RHE}}$ with a scan rate of $1 \mathrm{~V} \mathrm{~s}^{-1}$. In figure 6 the authors analyze the same catalyst region after a series of such treatments. For the first time it was found that under a certain treatment Pt NPs can detach from the carbon support although no sign of massive carbon corrosion was detectable. In fact, it was shown that particle detachment is the predominant degradation channel for the specific treatment and catalyst. Particle detachment being an almost exclusive degradation channel came as a surprise and spurred some discussion if the results could also be model by Pt dissolution [52]. It should be emphasized that comparing identical locations of the catalyst, enables size histograms of the same set of particles before and after treatment. In the series displayed in figure 6, it is demonstrated that the size distribution of the pristine Pt nanoparticles centers around $5 \mathrm{~nm}$. Upon treatment, the size of the nanoparticles changes only slightly towards higher values. In fact no particle could be identified that shrank under treatment, as expected for Pt dissolution. Either a particle was more or less unchanged after treatment, or it completely disappeared. As a consequence the number of particles on the carbon support changed significantly. Roughly, every second Pt nanoparticle disappeared upon the two sets of treatments. The analytical power of IL-TEM lies in the fact that from the change in the histogram a loss in Pt surface area can be calculated and directly be compared to the surface area loss in RDE measurements. By this comparison it was shown that the loss in particles in the histogram indeed correlated with loss in Pt surface area determined in independent RDE measurements. 

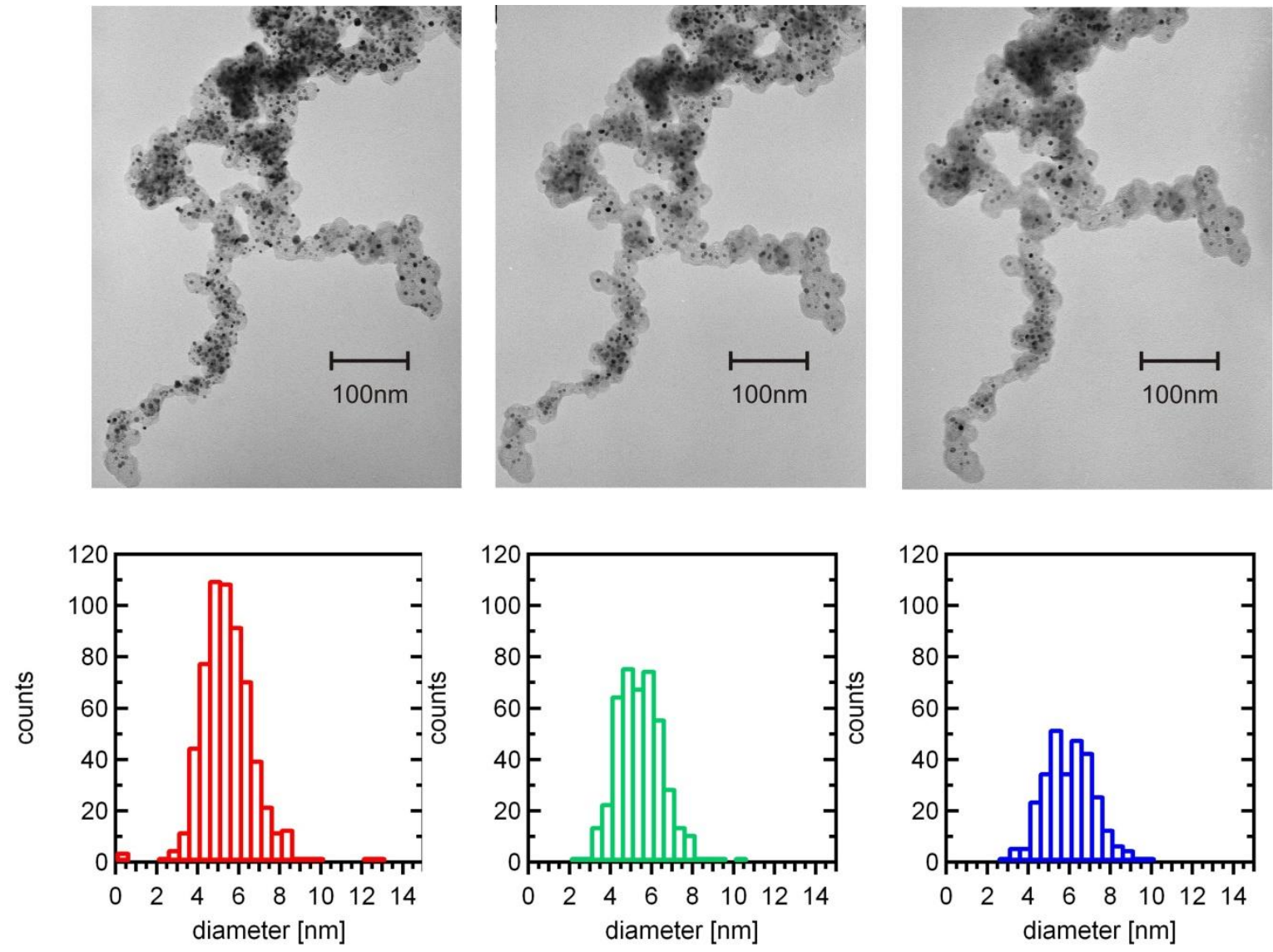

Figure 6. In the upper row an IL-TEM micrograph series of a commercial, high surface area carbon supported Pt catalyst (TEC10E50E-HT, TKK) is shown. The first image displays the catalyst before electrochemical treatment, the second after $2 \mathrm{~h}$ of treatment, and the third after a total of $4 \mathrm{~h}$ of treatment. In the lower row the corresponding particle size histograms analyzing several different micrographs are displayed. The electrochemical treatment consisted of potential cycling with $1.0 \mathrm{~V}$ $\mathrm{s}^{-1}$ between 0.4 and $1.4 \mathrm{~V}_{\mathrm{RHE}}$ (3600 cycles per treatment) at room temperature. The figure is adopted from ref. [43]. In this references also local enhancements (close ups) of the micrograph series are shown.

Following this study, that presented the proof of concept for the IL-TEM technique and the evidence of particle detachment as main degradation channel, the authors presented a series of investigations comparing different catalysts. In these studies it became clear that the results demonstrated in the first IL-TEM study were rather an exception than the rule. Comparing different commercial Pt /C catalyst samples it became evident that under the same electrochemical treatment different Pt/C samples can behave considerable different [53], see Figure 7. While on one Pt/C catalyst only particle detachment occurs, on the other $\mathrm{Pt} / \mathrm{C}$ catalyst clear evidence of particle migration and coalescence is seen. As a consequence, general claims of degradation channels for 
fuel cell catalysts, like Pt dissolution is the main reason for fuel cell catalyst degradation, should be avoided. Each degradation behavior depends on the catalyst itself and the treatment procedure. This result also means that degradation studies on commercial catalyst samples provide limited scientific insight. Although one may think that the difference in degradation demonstrated in Figure 7 is due to the difference in particle size. Such claims are not possible as for commercial samples in general no accurate information on the synthesis is given. The difference between the two samples might in fact be due to differences in temperature treatments and/support treatment during the synthesis of the two catalysts. How complex, and locally different the degradation of a fuel cell catalyst can be was demonstrated in a study of Meier et al. [54]. Applying the same AST treatment as in the studies discussed above, i.e. a fast potential cycling between 0.4 and $1.4 \mathrm{~V}_{\mathrm{RHE}}$ with a sweep rate of $1 \mathrm{~V} \mathrm{~s}^{-1}$, the authors observed clear evidence of particle migration and coalescence, particle detachment and $\mathrm{Pt}$ dissolution in close proximity to each other. As it is known that conventional carbon supports can be quite inhomogeneous, the result can be interpreted in a way that the local differences of the support control the degradation channel of the Pt particles. Without the use of IL-TEM it would have been impossible to reveal such differences in local degradation.

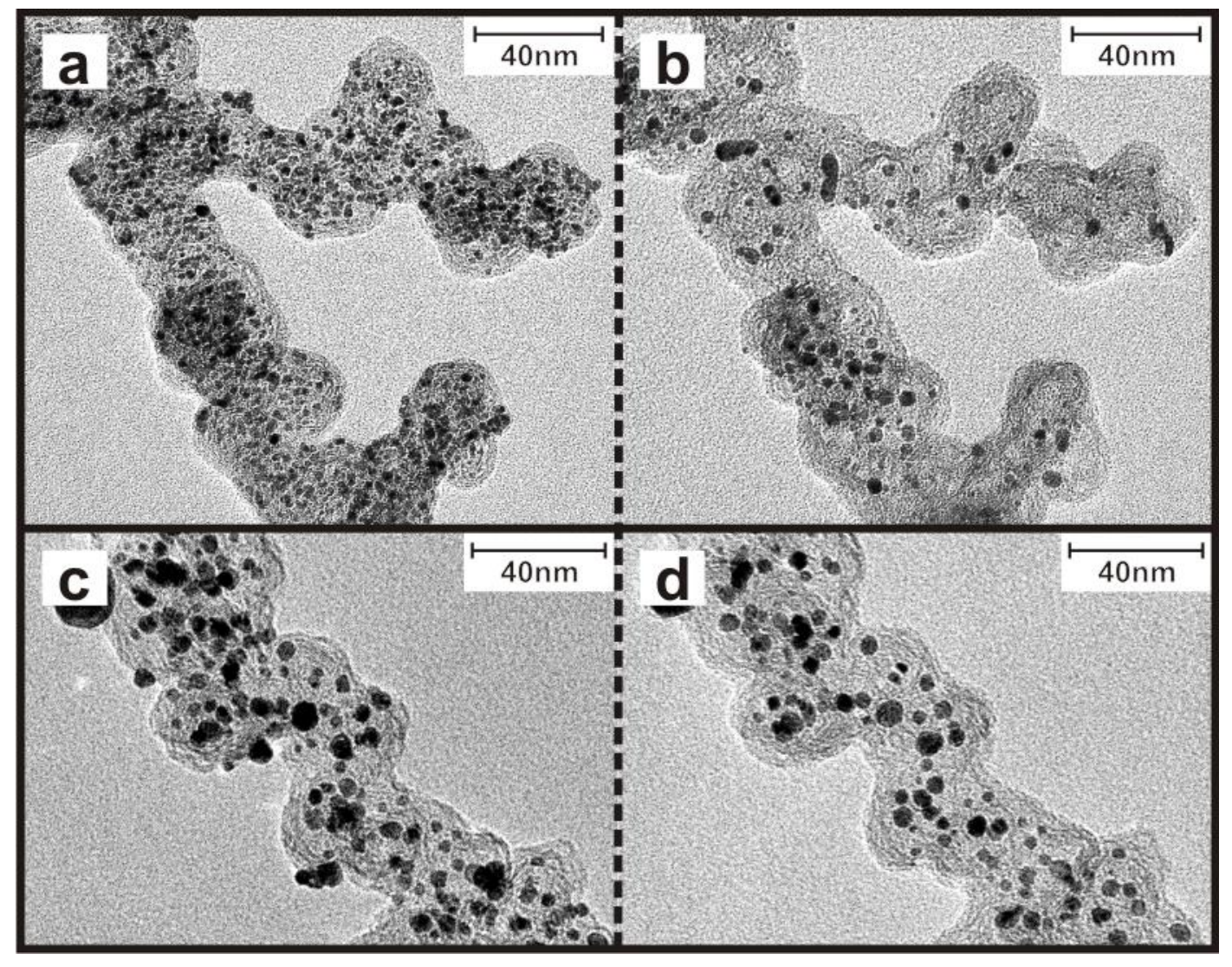


Figure 7. Comparison of IL-TEM micrographs of the commercial TEC10E50E and TEC10E50EHT catalysts (both TKK), respectively. a) and c) show the catalysts in their pristine state; b) and d) after an AST treatment consisting of 3600 potential cycles between 0.4 and $1.4 \mathrm{~V}_{\text {RHE }}$ with a scan speed of $1 \mathrm{~V} \mathrm{~s}^{-1}$. The figure is taken with permission from ref. [53].

That indeed the carbon significantly influences the degradation mechanism is demonstrated in figure 8. The authors compared two different carbon supports and evaluated the different degradation behavior with IL-TEM. It is seen that a specifically treated carbon support, can significantly reduce particle loss by providing a better anchoring for the Pt NPs [55]. This finding emphasizes the role of the support for improving the degradation resistance of fuel cell catalysts.
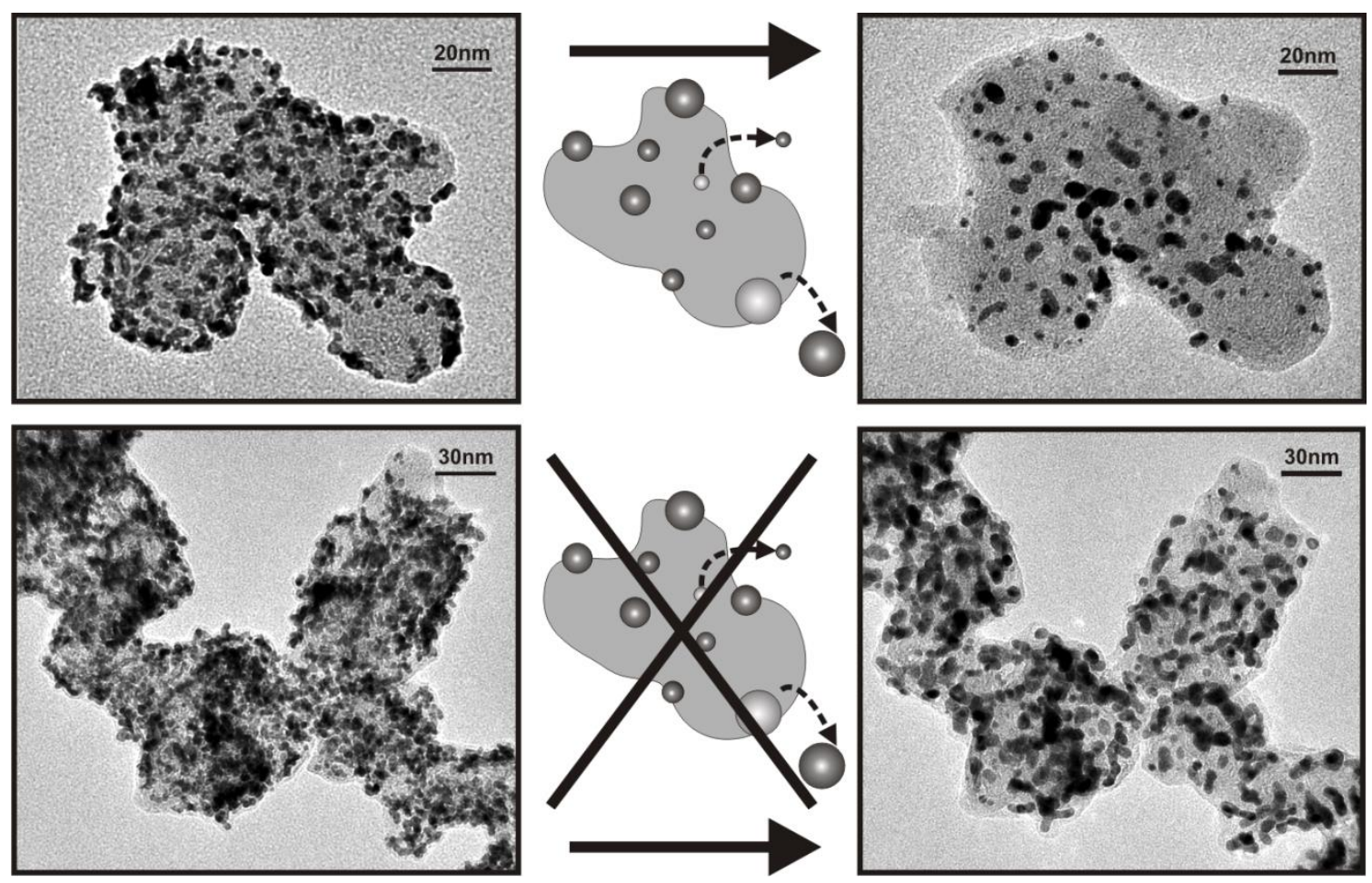

Figure 8. Comparison of IL-TEM micrographs of two Pt/C catalysts with differently treated carbon supports. It is clearly seen that on the catalyst shown in the lower row, particle detachment could be significantly suppressed. The AST treatment consisted of 3600 potential cycles between 0.4 and 1.4 $\mathrm{V}_{\mathrm{RHE}}$ with a scan speed of $1 \mathrm{~V} \mathrm{~s}^{-1}$. The figure is taken with permission from ref. [55].

It is well known that despite its noble character Pt can dissolve under electrochemical conditions experienced in a fuel cell. Interestingly, in these first IL-TEM studies, little direct evidence of Pt dissolution being the predominant reason for fuel cell catalyst degradation has been found. Despite the fact that Ostwald ripening, i.e. the dissolution of smaller particles and re-deposition onto larger ones, has been reported in many fuel cell studies to be the main degradation channel leading to a 
loss in performance due to the increase of the average NPs size in the catalyst. For example in degradation tests of MEAs clear experimental evidence of Ostwald ripening was provided by the detection of $\mathrm{Pt}$ that was deposited in the membrane [8]. Perez-Alonso et al. for the first time clearly reported Pt dissolution [50] in a IL-TEM study applying AST treatment. They performed potential cycling between 0.6 and $1.2 \mathrm{~V}_{\mathrm{RHE}}$ at $0.2 \mathrm{~V} \mathrm{~s}^{-1}$ in $0.1 \mathrm{M} \mathrm{HClO}_{4}$ using a commercial $\mathrm{Pt} / \mathrm{C}$ catalyst with an average Pt NPs particle size of $2.3 \mathrm{~nm}$. In their IL-TEM study a considerable loss of NPs was evident as well. But it could not be solely ascribe to NPs detachment, because also a considerable shrinking of the NPs size has been detected, see figure 9.

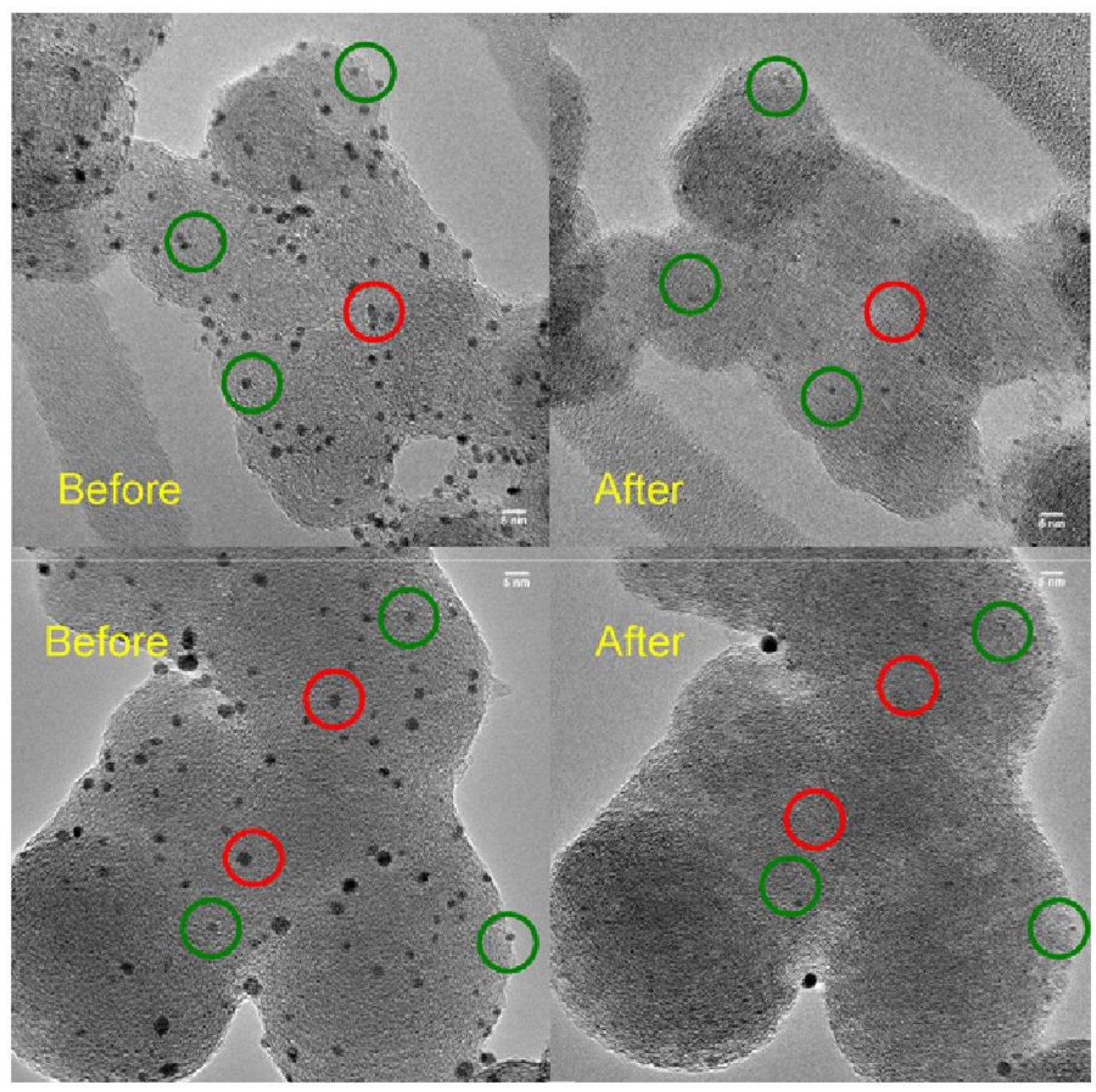

Figure 9. IL-TEM micrographs taken before and after accelerated corrosion test displaying clear signs of Pt dissolution. The $\mathrm{Pt} / \mathrm{C}$ sample was subjected to 3000 potential cycles between 0.6 and 1.2 $\mathrm{V}_{\mathrm{RHE}}$ at $200 \mathrm{mV} \mathrm{s}^{-1}$ in $0.1 \mathrm{M} \mathrm{HClO}_{4}$. The figure is taken with permission from ref. [50]. 
Such reduction in particle size is a strong indication of particle dissolution. It should be mentioned that the apparent (observed) Pt dissolution also depends on the thickness of the catalyst layer. In ILTEM the amount of catalyst on the TEM grid and thus the catalyst layer is minimal, see figure 4 . Else no proper imaging is possible. For thin catalyst layers such as the one used in [50], the apparent Pt dissolution can be enhanced as compared to thicker catalyst layers investigated in RDE degradation tests. In IL-TEM the likelihood of Pt ions being trapped in the catalyst layer inhibiting its diffusion into the bulk of the electrolyte is very low. Furthermore, Pt dissolution results in extremely low concentrations of Pt ions in the electrolyte solution so that re-deposition from the bulk electrolyte is extremely unlikely. The electrolyte acts as a sink for Pt ions. In RDE degradation studies as shown in figure 10 the apparent loss in surface increases upon AST treatment if the sample is rotated and decreases if the catalyst loading on the GC RDE tip is increased [56]. The same effect is also observed in scanning flow cells [57].
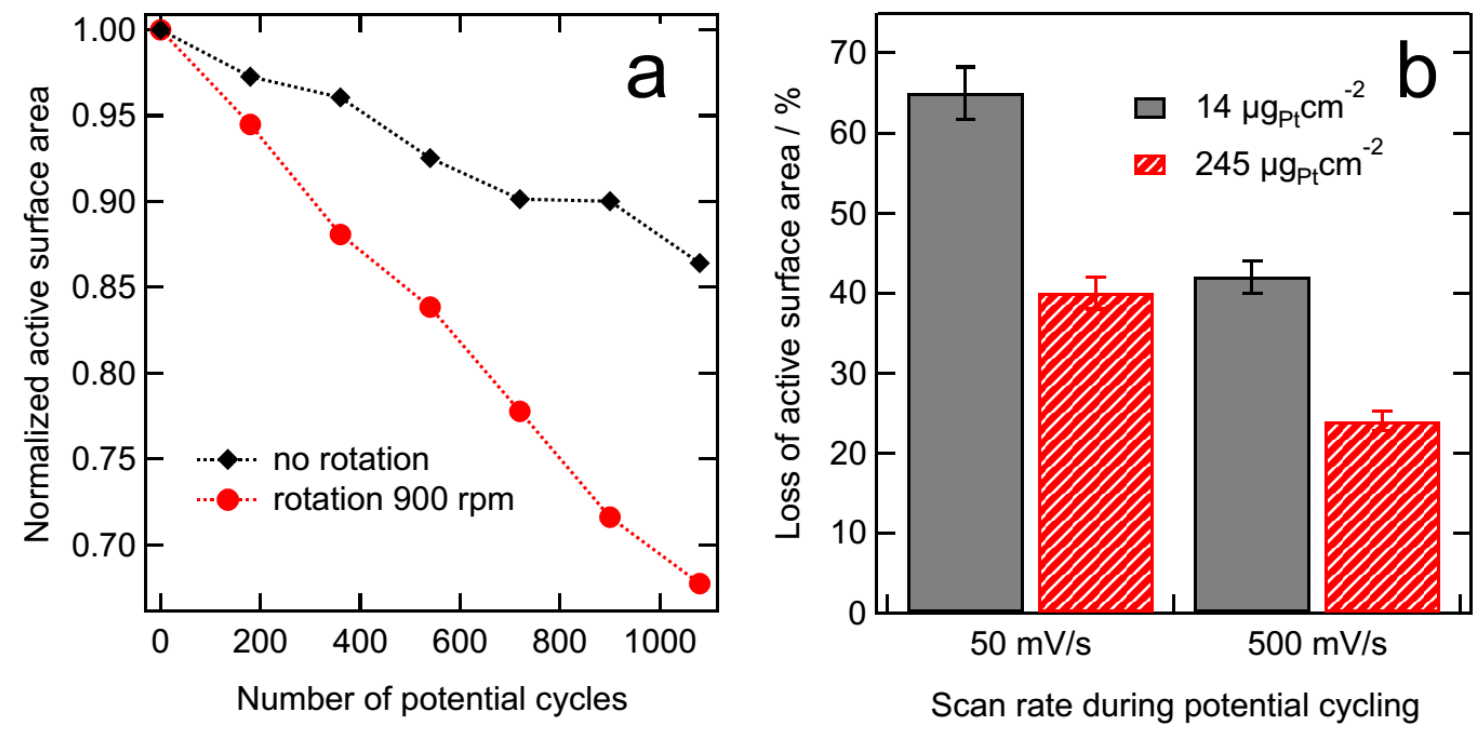

Figure 10. (a) Decrease in active surface area with the number of potential cycles with $1 \mathrm{Vs}^{-1}$ from 0.4 to $1.4 \mathrm{~V}_{\mathrm{RHE}}$ with and without rotation at $900 \mathrm{rpm}$. (b) Comparison of the loss of active surface area for the same potential cycling treatment $\left(0.4-1.4 \mathrm{~V}_{\mathrm{RHE}}, 1 \mathrm{Vs}^{-1}, 1800\right.$ cycles $)$ with different catalyst loadings (see legend) for two different scan rates (in both cases, $0.1 \mathrm{M} \mathrm{HClO} 4$ was used as electrolyte). The figure is taken with permission from ref. [58].

Last but not least a similar argument also applies for the scan speed. A fast scan speed increases the likelihood of re-deposition before the Pt ions can escape into the electrolyte. Thus a lower apparent dissolution can be expected at very high scan speeds. Most IL-TEM measurements apply fast potential scans to reduce the measurement time and to avoid contaminations in the half-cell, 
whereas in MEA degradation studies the cycling speed is relatively low [29]. The influence of fast potential cycling on the degradation mechanism is yet to be systematically studied by IL-TEM, but RDE studies demonstrate a clear change in surface area loss if the scan speed is varied, see figure 11.
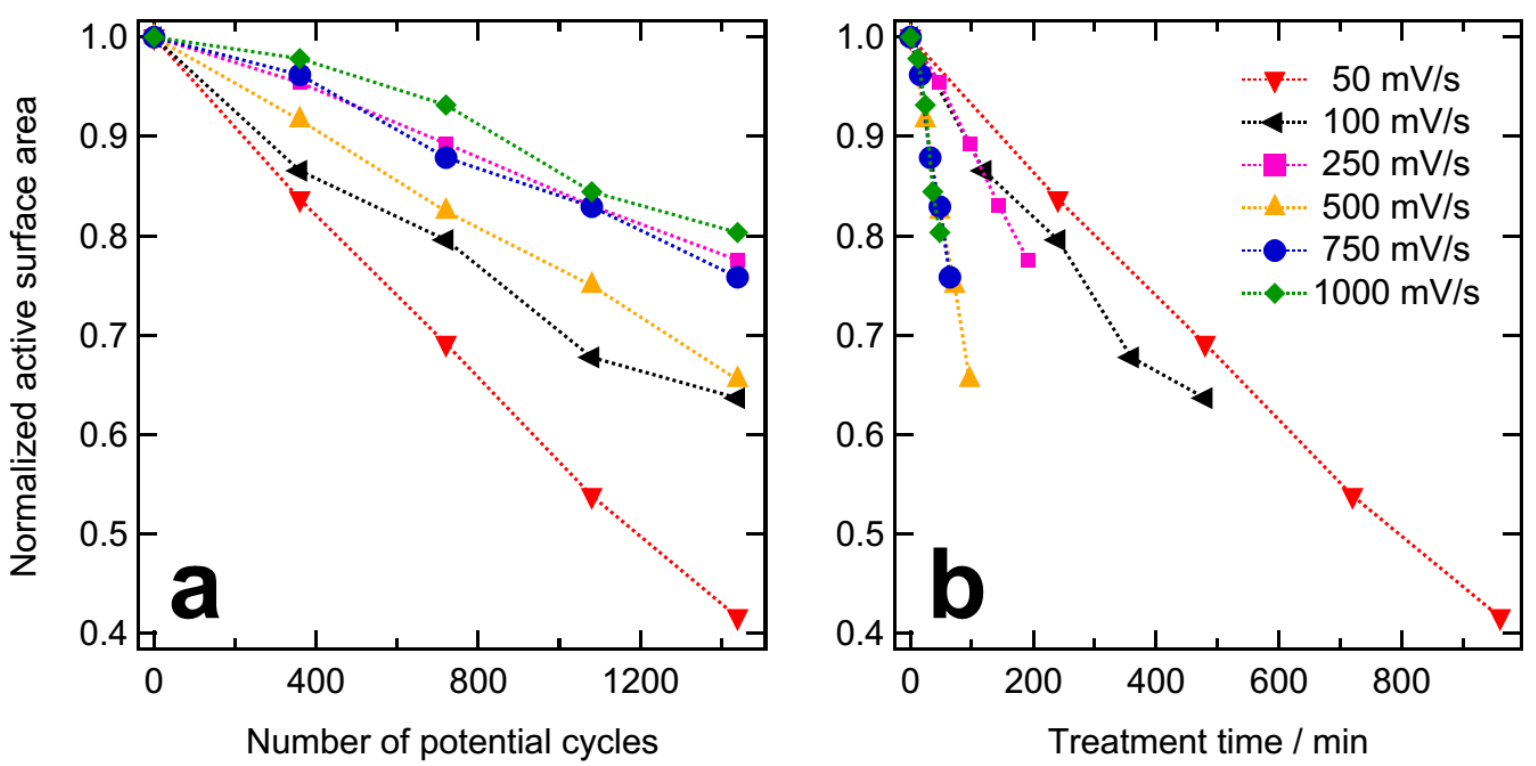

Figure 11. (a) Decrease in active surface area (determined using the integration of the $\mathrm{H}_{\text {upd }}$ area in cyclic voltammetry) with the number of cycles (a) and time (b) during a potential cycling treatment between 0.4 and $1.4 \mathrm{~V}_{\mathrm{RHE}}$ for 1800 cycles with the indicated scan rates. The figure is taken with permission from ref. [58].

So far, all half-cell studies we discussed were performed at room temperature. PEMFCs however operate around $80{ }^{\circ} \mathrm{C}$. It can be expected and indeed has been shown in half-cell measurements that temperature plays a significant role in degradation [59, 60]. The first IL-TEM study at elevated temperature was performed by Schlögl et al. The AST treatment consisted of holding the electrode potential at $1.3 \mathrm{~V}_{\mathrm{RHE}}$ and at $75^{\circ} \mathrm{C}$ [61]. In figure 12, it is demonstrated that such aging conditions are particularly demanding for the carbon support. Indication of massive carbon loss is seen. It seems that carbon support literally shrinks upon the treatment and that corrosion even leads to the formation of holes in the catalyst layer. 


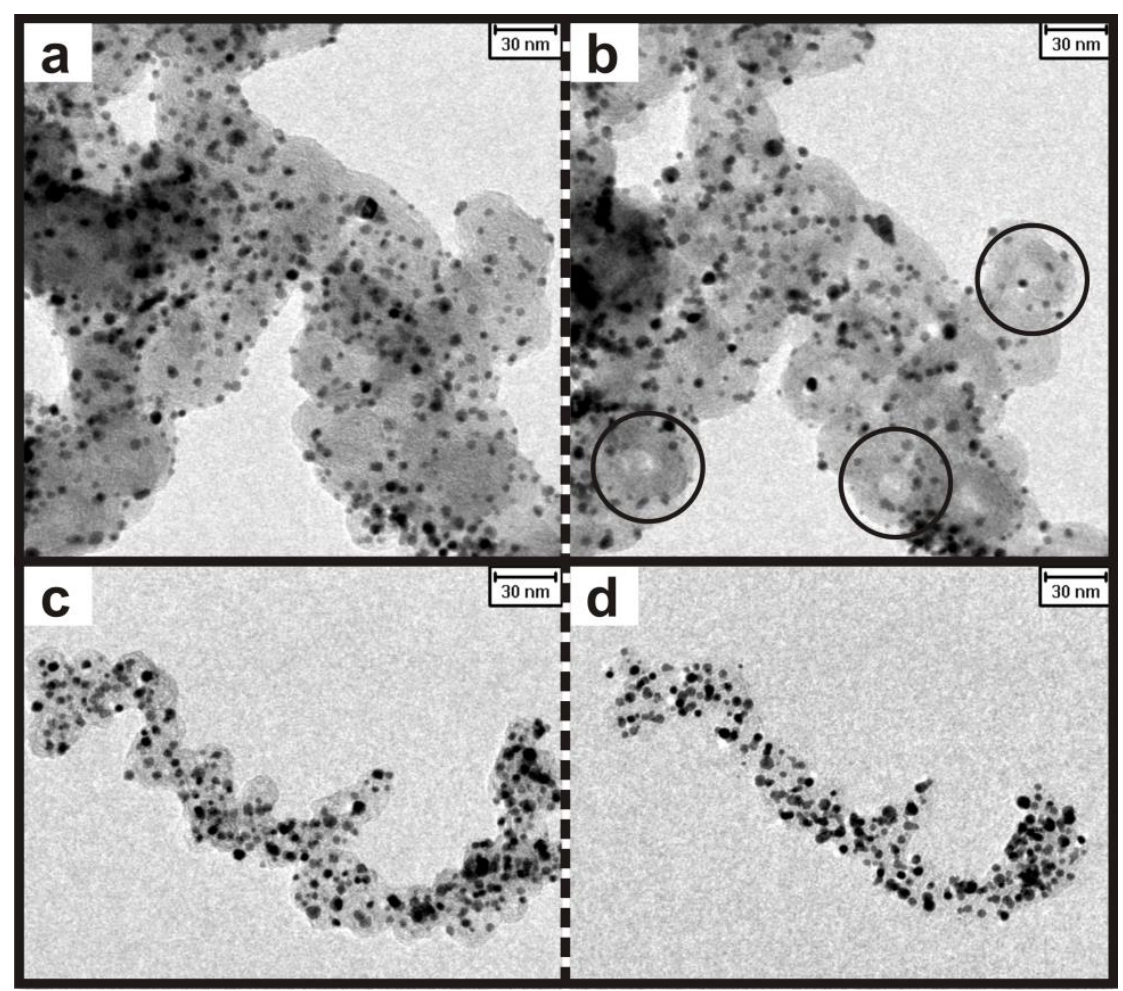

Figure 12. (a) IL-TEM study of a Pt/C catalyst before (a, c) and after (b, d) potentiostatic degradation measurements at $1.3 \mathrm{~V}_{\mathrm{RHE}}$ and $348 \mathrm{~K}$ for $16 \mathrm{~h}$ in $0.1 \mathrm{M} \mathrm{HClO}_{4}$. The figure is taken with permission from ref. [49].

With respect to the scarce number of IL-TEM investigations at elevated temperature, it has to be emphasized that increased temperature not only challenges the support but the TEM gold grid as well. In the same study, it was found that at elevated temperature, one needs to carefully limit the potential window to avoid gold dissolution of the TEM grid [49]. Figure 13, demonstrates that at holding working electrode at slightly higher potentials leads to significant dissolution of gold, which re-deposits onto the Pt nanoparticles. Without double-check of the particle composition by EDX, the result could have been easily confused with the growth of the catalyst particles. 


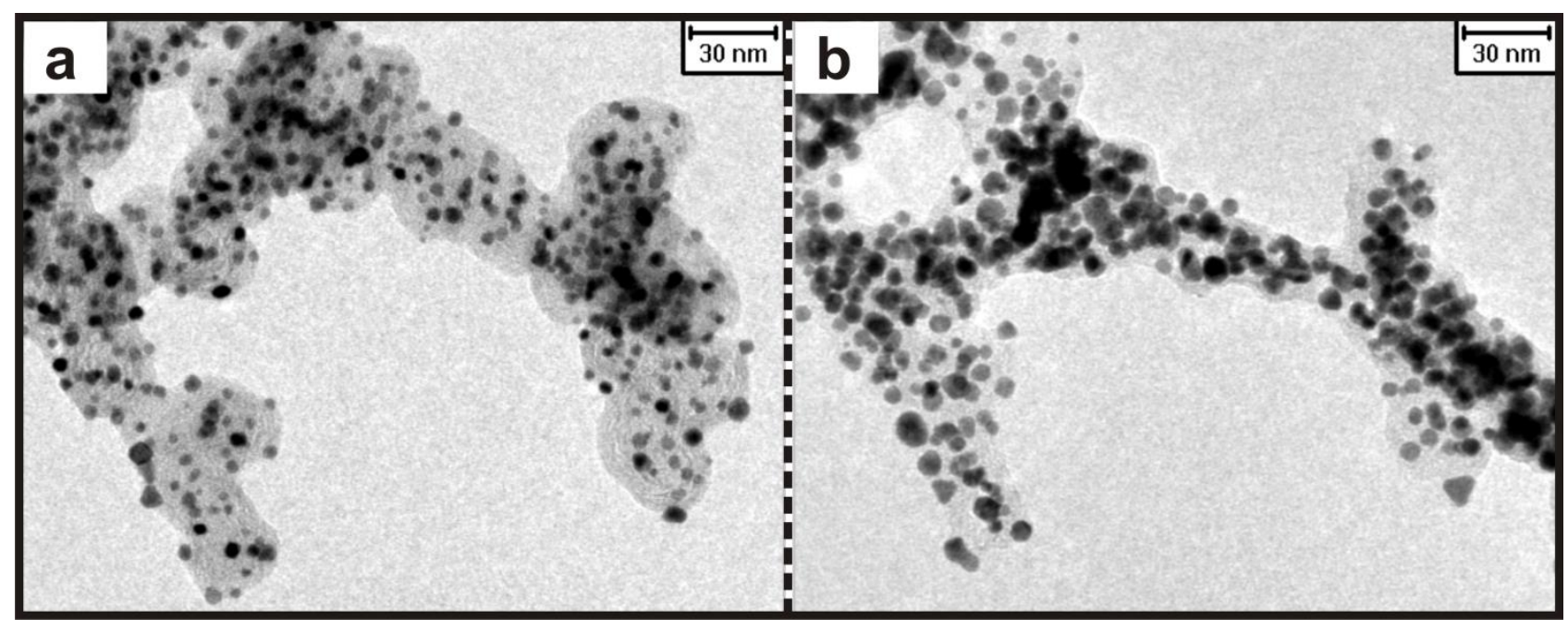

Figure 13. IL-TEM micrographs before (a) and after (b) potentiostatic degradation measurements at $1.4 \mathrm{~V}_{\mathrm{RHE}}$ and $333 \mathrm{~K}$ for $16 \mathrm{~h}$ in $0.1 \mathrm{M} \mathrm{HClO} 4$. The thinning of the high surface area carbon is observed along with a growth of Au nanoparticles (confirmed by EDX) due to dissolution of the Au TEM grid. The figure is taken with permission from ref. [49].

All these factors have to be taken into account when designing IL-TEM measurements and comparing results from IL-TEM and ex-situ half-cell RDE measurements to MEA tests. Due to the large variety of experimental conditions adopted $(\mathrm{pH}$, electrolyte concentration, temperature, applied potential, etc.), it is no trivial task to discern, which of the several degradation channels is main responsible for the performance loss of a catalyst. Depending on the aging conditions different degradation channels have been detected on the same catalysts material. IL-TEM studies showed that two or more degradation channels can be detected on the same catalysts [50,54,61]. A careful choice of the aging protocol and a systematic approach to the synthesis of $\mathrm{Pt} / \mathrm{C}$ catalysts is therefore essential to fundamentally investigate degradation mechanisms and to discerning which degradation channel is the main responsible for the performance loss - at least in half-cell measurements. Our group therefore adopted for our studies the AST protocol developed by the FCCJ that distinguishes two types of treatments to simulate conditions in a fuel cell: load cycling and start-stop conditions, see above, and a synthesis approach that uses colloidal nanoparticles as building blocks [62, 63]. The latter approach we dubbed tool-box synthesis [64]. These very recent developments already led to some advances in our understanding. For instance IL-TEM performed on such catalysts that have been synthesized under controlled conditions using a systematic approach demonstrated that under high potential excursion (i.e. 1-1.5 $\mathrm{V}_{\mathrm{RHE}}$ ) significant Pt nanoparticle detachment occurs, whereas under load cycling (i.e. 0.6-1 $\mathrm{V}_{\mathrm{RHE}}$ ) a more dominant particle migration and coalescence occured, see figure $14[65,66]$. 


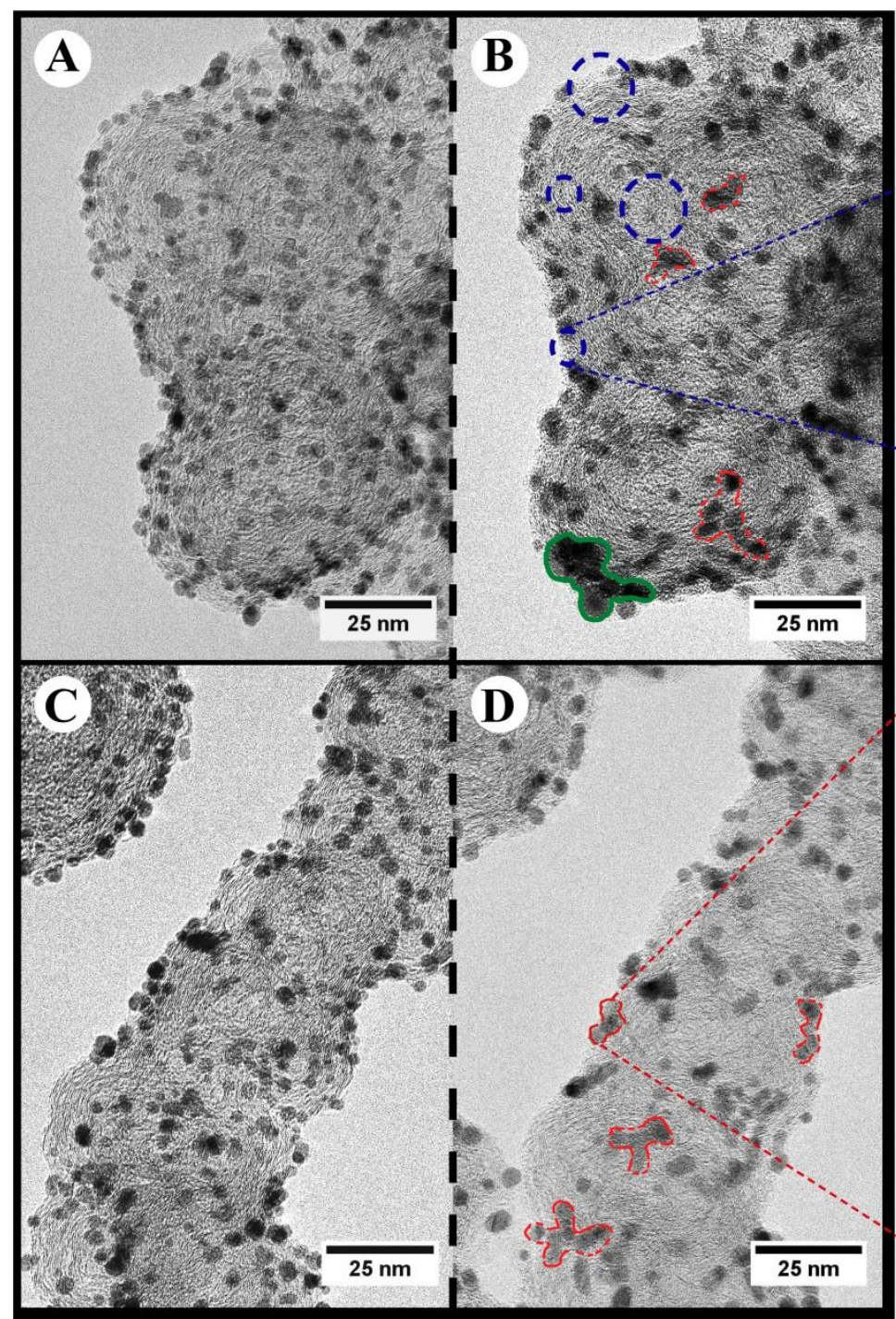

\section{Carbon corrosion}

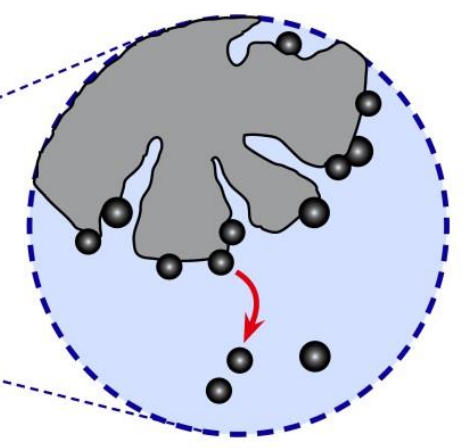

\section{Pt NP growth}

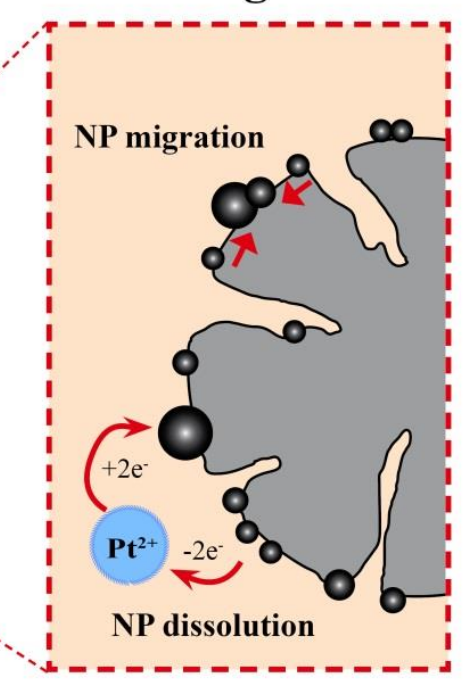

Figure 14. IL-TEM micrographs of a $30 \mathrm{wt}$. \% Pt/Ketjenblack catalyst before and after applying our standard AST protocols, i.e. 27,000 potential cycles between 1.0 and $1.5 \mathrm{~V}_{\mathrm{RHE}}$ with a sweep rate of $500 \mathrm{~m} \mathrm{~V} \mathrm{~s}^{-1}$ (A,B) and 9000 potential cycles between 0.6 and $1.0 \mathrm{~V}_{\mathrm{RHE}}$ with a holding time of 3:3 $\mathrm{s}(\mathrm{C}, \mathrm{D})$. The regions indicated by the blue color highlight particle detachment and the red indicated regions particle coalescence. The green marked region highlights regions that are suspected to be formed from gold deposits from dissolution and re-deposition of Au from the TEM grid. The figure is taken with permission from ref. [66].

Particle detachment could be clearly linked to the oxidation of the $\mathrm{C}$ support. Changing from one commercial support to the other or changing to an oxide based support leads to a significant change in the catalyst stability under the treatment simulating start-stop conditions, whereas no significant change was observed under the treatment simulating load cycle conditions $[66,67]$. Furthermore, it 
was shown that under the latter treatment the loss in surface area is independent of the amount of Pt on the carbon support (Pt loading in wt. \%), whereas for the treatment simulating start-stop conditions a clear increase of the ECSA loss with increasing Pt loading could be demonstrated.

With respect to the support, mesostructured carbon supports such as hollow graphitic spheres (HGS) have been discussed as alternative supports for Pt and PtM NPs. The idea is to confine the NPs in the pores of the support thus preventing coalescence and Pt detachment $[68,69]$. Using ILTEM and IL-STEM the authors were able to prove the concept of pore confinement in HGS.

\section{Outlook}

Since the publication of the first IL-TEM study considerable improvements have been made in the systematic ex-situ investigation of fuel cell catalysts degradation. The introduction of more controlled AST protocols and a systematic approach to catalyst synthesize in combination with ILTEM will allow us to describe degradation of industrial catalysts in a more comparable, controlled way. But also the extension and advancement of IL-TEM to other microscopy techniques has to be highlighted. IL-SEM, i.e. using scanning electron microscopy instead of transmission electron microscopy, has been recently introduced [70, 71] offering additional flexibility to the type of sample under investigation and the combination of different methods. IL-SEM allows the investigation of the same sample that has been employed in RDE tests of the activity or the loss in ECSA. By the means of 3D visualization, electron tomography (IL-tomography) for the first time allowed to visualize the trajectories of the NPs onto the $\mathrm{C}$ support $[54,72,73]$. An interesting development could be to track morphological changes of the catalyst layer on a larger, mesoscopic scale. Recent investigations showed that the activity performance of catalysts evaluated by RDE significantly depends on the ink formulation and the resulting catalyst film structure [21]. Thus linking the structure of the catalyst layer and its changes to the performance would be an interesting topic that could provide a link between ex-situ and in-situ studies.

Fundamental investigations of particle model systems, by comparison, are only in its infancy. A more straight forward methodology to prepare high quality samples and an automatic analysis of large amounts of particles before and after treatment will be essential for this approach. For solving these challenges, the synthesis approach for colloidal nanoparticles as building blocks and the application of STEM have promising potential.

\section{Acknowledgment}


M.A. would like to acknowledge the major funding sources received in the last years making this work possible: The Danish DSF through the 4M center, the Danish DFF through grant no.10081337, the European Union Seventh Framework Program (FP7/2007-2013) under Grant Agreement No. 309741 and the German DFG through an Emmy Noether grant.

\section{References}

[1] H.A. Gasteiger, N.M. Markovic, Just a Dream-or Future Reality?, Science, 324 (2009) 48-49.

[2] C. Chen, Y.J. Kang, Z.Y. Huo, Z.W. Zhu, W.Y. Huang, H.L.L. Xin, J.D. Snyder, D.G. Li, J.A. Herron, M. Mavrikakis, M.F. Chi, K.L. More, Y.D. Li, N.M. Markovic, G.A. Somorjai, P.D. Yang, V.R. Stamenkovic, Highly Crystalline Multimetallic Nanoframes with Three-Dimensional Electrocatalytic Surfaces, Science, 343 (2014) 1339-1343.

[3] C.H. Cui, L. Gan, M. Heggen, S. Rudi, P. Strasser, Compositional segregation in shaped Pt alloy nanoparticles and their structural behaviour during electrocatalysis, Nature Materials, 12 (2013) 765-771.

[4] M.K. Debe, Electrocatalyst approaches and challenges for automotive fuel cells, Nature, 486 (2012) 4351.

[5] R. Borup, J. Meyers, B. Pivovar, Y.S. Kim, R. Mukundan, N. Garland, D. Myers, M. Wilson, F. Garzon, D. Wood, P. Zelenay, K. More, K. Stroh, T. Zawodzinski, J. Boncella, J.E. McGrath, M. Inaba, K. Miyatake, M. Hori, K. Ota, Z. Ogumi, S. Miyata, A. Nishikata, Z. Siroma, Y. Uchimoto, K. Yasuda, K.i. Kimijima, N. Iwashita, Scientific Aspects of Polymer Electrolyte Fuel Cell Durability and Degradation, Chem. Rev., 107 (2007) 39043951.

[6] F.N. Büchi, M. Inaba, T.J. Schmidt, Polymer electrolyte fuel cell durability, Springer2009.

[7] W. Bi, G.E. Gray, T.F. Fuller, PEM fuel cell Pt/C dissolution and deposition in nafion electrolyte, Electrochemical and Solid State Letters, 10 (2007) B101-B104.

[8] P.J. Ferreira, G.J. la O', Y. Shao-Horn, D. Morgan, R. Makharia, S. Kocha, H.A. Gasteiger, Instability of $\mathrm{Pt} / \mathrm{C}$ Electrocatalysts in Proton Exchange Membrane Fuel Cells: A Mechanistic Investigation, Journal of The Electrochemical Society, 152 (2005) A2256-A2271.

[9] A.J. Bard, L.R. Faulkner, Electrochemical methods: fundamentals and applications, Wiley New York1980. [10] H.A. Gasteiger, S.S. Kocha, B. Sompalli, F.T. Wagner, Activity benchmarks and requirements for Pt, Ptalloy, and non-Pt oxygen reduction catalysts for PEMFCs, Applied Catalysis B: Environmental, 56 (2005) 935 .

[11] S.J. Ashton, M. Arenz, Comparative DEMS study on the electrochemical oxidation of carbon blacks, Journal of Power Sources, 217 (2012) 392-399.

[12] S.J. Ashton, M. Arenz, A DEMS study on the electrochemical oxidation of a high surface area carbon black, Electrochemistry Communications, 13 (2011) 1473-1475.

[13] M. Heinen, Y. Chen, Z. Jusys, R. Behm, In situ ATR-FTIRS coupled with on-line DEMS under controlled mass transport conditions-A novel tool for electrocatalytic reaction studies, Electrochimica acta, 52 (2007) 5634-5643.

[14] Z. Jusys, H. Massong, H. Baltruschat, A New Approach for Simultaneous DEMS and EQCM: Electrooxidation of Adsorbed CO on Pt and Pt-Ru, Journal of the electrochemical Society, 146 (1999) 1093-1098.

[15] J. Willsau, J. Heitbaum, The influence of Pt-activation on the corrosion of carbon in gas diffusion electrodes-A dems study, Journal of Electroanalytical Chemistry and Interfacial Electrochemistry, 161 (1984) 93-101.

[16] K.J.J. Mayrhofer, M. Arenz, Catalyst ageing and degradation in polymer electrolyte membrane fuel cells, Polymer Electrolyte Membrane and Direct Methanol Fuel Cell Technology: Fundamentals and Performance of Low Temperature Fuel Cells, Woodhead publishing Series in Energy no. 30; ISBN 184569 77312012. 
[17] G.K.H. Wiberg, The development of a state-of-the-art experimental setup demonstrated by the investigation of fuel cell reactions in alkaline electrolyte, Technische Universität München, 2010.

[18] T. Schmidt, H. Gasteiger, R. Behm, Rotating disk electrode measurements on the CO tolerance of a high-surface area Pt/vulcan carbon fuel cell catalyst, Journal of The Electrochemical Society, 146 (1999) 1296-1304.

[19] U. Paulus, T. Schmidt, H. Gasteiger, R. Behm, Oxygen reduction on a high-surface area Pt/Vulcan carbon catalyst: a thin-film rotating ring-disk electrode study, Journal of Electroanalytical Chemistry, 495 (2001) 134-145.

[20] K. Mayrhofer, D. Strmcnik, B.B. Blizanac, V. Stamenkovic, M. Arenz, N.M. Markovic, Measurement of oxygen reduction activities via the rotating disc electrode method: From Pt model surfaces to carbonsupported high surface area catalysts, Electrochimica Acta, 53 (2008) 3181-3188.

[21] K. Shinozaki, J.W. Zack, S. Pylypenko, B.S. Pivovar, S.S. Kocha, Oxygen Reduction Reaction Measurements on Platinum Electrocatalysts Utilizing Rotating Disk Electrode Technique, Journal of the Electrochemical Society, 162 (2015) F1384-F1396.

[22] K. Shinozaki, J.W. Zack, S. Pylypenko, R.M. Richards, B.S. Pivovar, S.S. Kocha, Benchmarking the oxygen reduction reaction activity of Pt-based catalysts using standardized rotating disk electrode methods, Int J Hydrogen Energ, 40 (2015) 16820-16830.

[23] L. Xing, M.A. Hossain, M. Tian, D. Beauchemin, K.T. Adjemian, G. Jerkiewicz, Platinum Electrodissolution in Acidic Media upon Potential Cycling, Electrocatalysis, 5 (2013) 96-112.

[24] P.J. Kulesza, W. Lu, L.R. Faulkner, Cathodic fabrication of platinum microparticles via anodic dissolution of a platinum counter-electrode: Electrocatalytic probing and surface analysis of dispersed platinum, Journal of Electroanalytical Chemistry, 336 (1992) 35-44.

[25] L. Xing, M.A. Hossain, M. Tian, D. Beauchemin, K. Adjemian, G. Jerkiewicz, Platinum Electro-dissolution in Acidic Media upon Potential Cycling, Electrocatalysis, 5 (2014) 96-112.

[26] S. Cherevko, G.P. Keeley, S. Geiger, A.R. Zeradjanin, N. Hodnik, N. Kulyk, K.J.J. Mayrhofer, Dissolution of Platinum in the Operational Range of Fuel Cells, ChemElectroChem, 2 (2015) 1471-1478.

[27] N. Hodnik, C. Baldizzone, S. Cherevko, A. Zeradjanin, K.J.J. Mayrhofer, The Effect of the Voltage Scan Rate on the Determination of the Oxygen Reduction Activity of Pt/C Fuel Cell Catalyst, Electrocatalysis, 6 (2015) 237-241.

[28] A. liyama, K. Shinohara, S. Iguchi, A. Daimaru, Membranes and catalyst performance targets for automotive fuel cells, Handbook of Fuel Cells, John Wiley \& Sons, Ltd2010.

[29] A. Ohma, K. Shinohara, A. liyama, T. Yoshida, A. Daimaru, Membrane and Catalyst Performance Targets for Automotive Fuel Cells by FCCJ Membrane, Catalyst, MEA WG, ECS Transactions, 41 (2011) 775-784.

[30] DOE, Rotating disk-electrode aqueous electrolyte accelerated stress test protocols developed by the DOE Durability Working Group for platinum group metal (PGM) electrocatalyst/support durability evaluation; http://energy.gov/eere/fuelcells/downloads/rotating-disk-electrode-aqueous-electrolyteaccelerated-stress-tests-pgm, 2011.

[31] C.A. Reiser, L. Bregoli, T.W. Patterson, S.Y. Jung, J.D. Yang, M.L. Perry, T.D. Jarvi, A reverse-current decay mechanism for fuel cells, Electrochemical and Solid-State Letters, 8 (2005) A273-A276.

[32] R.M. Darling, J.P. Meyers, Mathematical model of platinum movement in PEM fuel cells, Journal of the Electrochemical Society, 152 (2005) A242-A247.

[33] R.M. Darling, J.P. Meyers, Kinetic model of platinum dissolution in PEMFCs, Journal of the Electrochemical Society, 150 (2003) A1523-A1527.

[34] M. Uchimura, S.S. Kocha, The impact of cycle profile on PEMFC durability, (2007).

[35] S. Cherevko, N. Kulyk, K.J.J. Mayrhofer, Durability of platinum-based fuel cell electrocatalysts: Dissolution of bulk and nanoscale platinum, Nano Energy; http://dx.doi.org/10.1016/j.nanoen.2016.03.005.

[36] K.J.J. Mayrhofer, B.B. Blizanac, M. Arenz, V.R. Stamenkovic, P.N. Ross, N.M. Markovic, The impact of geometric and surface electronic properties of Pt-catalysts on the particle size effect in electocatalysis, J Phys Chem B, 109 (2005) 14433-14440. 
[37] G.K.H. Wiberg, K.J.J. Mayrhofer, M. Arenz, Investigation of the Oxygen Reduction Activity on Silver - A Rotating Disc Electrode Study, Fuel Cells, 10 (2010) 575-581.

[38] V.R. Stamenkovic, B. Fowler, B.S. Mun, G. Wang, P.N. Ross, C.A. Lucas, N.M. Marković, Improved Oxygen Reduction Activity on Pt3Ni(111) via Increased Surface Site Availability, Science, 315 (2007) 493497.

[39] Y.-C. Park, K. Kakinuma, M. Uchida, H. Uchida, M. Watanabe, Deleterious effects of interim cyclic voltammetry on $\mathrm{Pt} / \mathrm{carbon}$ black catalyst degradation during start-up/shutdown cycling evaluation, Electrochimica Acta, 123 (2014) 84-92.

[40] C.A. Rice, P. Urchaga, A.O. Pistono, B.W. McFerrin, B.T. McComb, J. Hu, Platinum Dissolution in Fuel Cell Electrodes: Enhanced Degradation from Surface Area Assessment in Automotive Accelerated Stress Tests, Journal of The Electrochemical Society, 162 (2015) F1175-F1180.

[41] A.A. Topalov, A.R. Zeradjanin, S. Cherevko, K.J.J. Mayrhofer, The impact of dissolved reactive gases on platinum dissolution in acidic media, Electrochemistry Communications, 40 (2014) 49-53.

[42] K.J. Mayrhofer, S.J. Ashton, J.C. Meier, G.K. Wiberg, M. Hanzlik, M. Arenz, Non-destructive transmission electron microscopy study of catalyst degradation under electrochemical treatment, Journal of Power Sources, 185 (2008) 734-739.

[43] K.J. Mayrhofer, J.C. Meier, S.J. Ashton, G.K. Wiberg, F. Kraus, M. Hanzlik, M. Arenz, Fuel cell catalyst degradation on the nanoscale, Electrochemistry Communications, 10 (2008) 1144-1147.

[44] S. Kunz, K. Hartl, M. Nesselberger, F.F. Schweinberger, G. Kwon, M. Hanzlik, K.J.J. Mayrhofer, U. Heiz, $M$. Arenz, Size-selected clusters as heterogeneous model catalysts under applied reaction conditions, Phys Chem Chem Phys, 12 (2010) 10288-10291.

[45] K. Hartl, M. Nesselberger, K.J.J. Mayrhofer, S. Kunz, F.F. Schweinberger, G. Kwon, M. Hanzlik, U. Heiz, M. Arenz, Electrochemically induced nanocluster migration, Electrochimica Acta, 56 (2010) 810-816.

[46] M. Nesselberger, M. Roefzaad, R.F. Hamou, P.U. Biedermann, F.F. Schweinberger, S. Kunz, K. Schloegl, G.K.H. Wiberg, S. Ashton, U. Heiz, K.J.J. Mayrhofer, M. Arenz, The effect of particle proximity on the oxygen reduction rate of size-selected platinum clusters, Nature Materials, 12 (2013) 919-924.

[47] J.C. Meier, C. Galeano, I. Katsounaros, A.A. Topalov, A. Kostka, F. Schüth, K.J.J. Mayrhofer, Degradation Mechanisms of Pt/C Fuel Cell Catalysts under Simulated Start-Stop Conditions, ACS Catalysis, 2 (2012) 832843.

[48] N. Hodnik, M. Zorko, M. Bele, S. Hočevar, M. Gaberšček, Identical Location Scanning Electron Microscopy: A Case Study of Electrochemical Degradation of PtNi Nanoparticles Using a New Nondestructive Method, The Journal of Physical Chemistry C, 116 (2012) 21326-21333.

[49] K. Schlogl, K.J.J. Mayrhofer, M. Hanzlik, M. Arenz, Identical-location TEM investigations of Pt/C electrocatalyst degradation at elevated temperatures, Journal of Electroanalytical Chemistry, 662 (2011) 355-360.

[50] F.J. Perez-Alonso, C.F. Elkjær, S.S. Shim, B.L. Abrams, I.E.L. Stephens, I. Chorkendorff, Identical locations transmission electron microscopy study of $\mathrm{Pt} / \mathrm{C}$ electrocatalyst degradation during oxygen reduction reaction, Journal of Power Sources, 196 (2011) 6085-6091.

[51] S.B. Simonsen, I. Chorkendorff, S. Dahl, M. Skoglundh, J. Sehested, S. Helveg, Direct Observations of Oxygen-induced Platinum Nanoparticle Ripening Studied by In Situ TEM, Journal of the American Chemical Society, 132 (2010) 7968-7975.

[52] S.G. Rinaldo, J. Stumper, M. Eikerling, Physical Theory of Platinum Nanoparticle Dissolution in Polymer Electrolyte Fuel Cells, Journal of Physical Chemistry C, 114 (2010) 5773-5785.

[53] K. Schlogl, M. Hanzlik, M. Arenz, Comparative IL-TEM Study Concerning the Degradation of Carbon Supported Pt-Based Electrocatalysts, Journal of the Electrochemical Society, 159 (2012) B677-B682.

[54] J.C. Meier, C. Galeano, I. Katsounaros, A.A. Topalov, A. Kostka, F. Schüth, K.J. Mayrhofer, Degradation mechanisms of Pt/C fuel cell catalysts under simulated start-stop conditions, ACS Catalysis, 2 (2012) 832843.

[55] K. Hartl, M. Hanzlik, M. Arenz, IL-TEM investigations on the degradation mechanism of Pt/C electrocatalysts with different carbon supports, Energy \& Environmental Science, 4 (2011) 234-238. 
[56] T. Nagai, H. Murata, Y. Morimoto, Influence of Experimental Conditions on the Catalyst Degradation in the Durability Test, Journal of The Electrochemical Society, 161 (2014) F789-F794.

[57] G.P. Keeley, S. Cherevko, K.J.J. Mayrhofer, The Stability Challenge on the Pathway to Low and UltraLow Platinum Loading for Oxygen Reduction in Fuel Cells, ChemElectroChem, 3 (2016) 51-54.

[58] K. Schlogl, Identical location transmission electron microscopy in combination with rotating disc electrode measurements - the activity of fuel cell catalysts and their degradation, Fakultät für Chemie, Technical University Munich, http://nbn-resolving.de/urn/resolver.pl?urn:nbn:de:bvb:91-diss-20110720-1079138-1-9 2011.

[59] W. Bi, T.F. Fuller, Temperature effects on PEM fuel cells Pt/C catalyst degradation, Journal of The Electrochemical Society, 155 (2008) B215-B221.

[60] A. Riese, D. Banham, S.Y. Ye, X.L. Sun, Accelerated Stress Testing by Rotating Disk Electrode for Carbon Corrosion in Fuel Cell Catalyst Supports, Journal of the Electrochemical Society, 162 (2015) F783-F788.

[61] K. Schlögl, K.J.J. Mayrhofer, M. Hanzlik, M. Arenz, Identical-location TEM investigations of Pt/C electrocatalyst degradation at elevated temperatures, Journal of Electroanalytical Chemistry, 662 (2011) 355-360.

[62] Y. Wang, J.W. Ren, K. Deng, L.L. Gui, Y.Q. Tang, Preparation of tractable platinum, rhodium, and ruthenium nanoclusters with small particle size in organic media, Chem Mater, 12 (2000) 1622-1627.

[63] Y. Wang, J.L. Zhang, X.D. Wang, J.W. Ren, B.J. Zuo, Y.Q. Tang, Metal nanoclusters stabilized with simple ions and solvents - promising building blocks for future catalysts, Topics in Catalysis, 35 (2005) 35-41.

[64] J. Speder, L. Altmann, M. Roefzaad, M. Baumer, J.J.K. Kirkensgaard, K. Mortensen, M. Arenz, Pt based PEMFC catalysts prepared from colloidal particle suspensions - a toolbox for model studies, Phys Chem Chem Phys, 15 (2013) 3602-3608.

[65] A. Zana, J. Speder, M. Roefzaad, L. Altmann, M. Bäumer, M. Arenz, Probing degradation by IL-TEM: the influence of stress test conditions on the degradation mechanism, Journal of The Electrochemical Society, 160 (2013) F608-F615.

[66] J. Speder, A. Zana, I. Spanos, J.J. Kirkensgaard, K. Mortensen, M. Hanzlik, M. Arenz, Comparative degradation study of carbon supported proton exchange membrane fuel cell electrocatalysts-The influence of the platinum to carbon ratio on the degradation rate, Journal of Power Sources, 261 (2014) 14-22.

[67] A. Zana, C. Rudiger, J. Kunze-Liebhauser, G. Granozzi, N.E.A. Reeler, T. Vosch, J.J.K. Kirkensgaard, M. Arenz, Core-shell TiO2@C: towards alternative supports as replacement for high surface area carbon for PEMFC catalysts, Electrochimica Acta, 139 (2014) 21-28.

[68] C. Galeano, J.C. Meier, V. Peinecke, H. Bongard, I. Katsounaros, A.A. Topalov, A. Lu, K.J.J. Mayrhofer, F. Schüth, Toward Highly Stable Electrocatalysts via Nanoparticle Pore Confinement, Journal of the American Chemical Society, 134 (2012) 20457-20465.

[69] C. Baldizzone, S. Mezzavilla, H.W.P. Carvalho, J.C. Meier, A.K. Schuppert, M. Heggen, C. Galeano, J.-D. Grunwaldt, F. Schüth, K.J.J. Mayrhofer, Confined-Space Alloying of Nanoparticles for the Synthesis of Efficient PtNi Fuel-Cell Catalysts, Angewandte Chemie International Edition, 53 (2014) 14250-14254.

[70] N. Hodnik, B. Jozinovic, M. Zorko, M. Gaberscek, Stability of Commercial Pt/C Low Temperature Fuel Cell Catalyst: Electrochemical IL-SEM Study, Acta Chim Slov, 61 (2014) 280-283.

[71] N. Hodnik, M. Zorko, B. Jozinovic, M. Bele, G. Drazic, S. Hocevar, M. Gaberscek, Severe accelerated degradation of PEMFC platinum catalyst: A thin film IL-SEM study, Electrochemistry Communications, 30 (2013) 75-78.

[72] Y. Yu, H.L. Xin, R. Hovden, D. Wang, E.D. Rus, J.A. Mundy, D.A. Muller, H.D. Abruña, Three-Dimensional Tracking and Visualization of Hundreds of Pt-Co Fuel Cell Nanocatalysts During Electrochemical Aging, Nano Letters, 12 (2012) 4417-4423.

[73] N. Hodnik, C. Jeyabharathi, J.C. Meier, A. Kostka, K.L. Phani, A. Rečnik, M. Bele, S. Hočevar, M. Gaberšček, K.J. Mayrhofer, Effect of ordering of PtCu 3 nanoparticle structure on the activity and stability for the oxygen reduction reaction, Phys Chem Chem Phys, 16 (2014) 13610-13615. 